\title{
HERITABILITY OF END-USE QUALITY AND BIOFORTIFICATION CHARACTERISTICS IN LINE X TESTER BREAD WHEAT (Triticum aestivum L.) CROSSES
}

\author{
KUTLU, I. \\ Department of Biosystem Engineering, Faculty of Agriculture, Eskisehir Osmangazi University \\ 26160 Eskisehir, Turkey \\ (e-mail: ikutlu@ogu.edu.tr; phone: +90-222-3242991; fax: +90-222-3242990)
}

(Received 29 $9^{\text {th }}$ Aug 2018; accepted $11^{\text {th }}$ Oct 2018)

\begin{abstract}
Wheat (Triticum aestivum L.) is an important resource of dietary energy and protein for the growing world population and its potential to reduce micronutrient-related malnutrition can be increased via improving the genetically micronutrient-rich wheat varieties. The study aimed to evaluate "line $\mathrm{x}$ tester" bread wheat hybrids in terms of the physical quality criteria affecting wheat flour yield, protein and biofortification associated nutrient element contents. In addition, it was tried to determine the gene effects that play a role in the inheritance of biofortification and end-use quality traits. Twenty-eight $F_{1}$ hybrids which were obtained by crossing seven lines and four testers were evaluated along with parents in Eskisehir, Turkey during 2016-17 growing period for mentioned traits. It has been determined that the effects of non-additive genes are dominant in the inheritance of the traits examined. It would be wise to leave the selection for these properties to future generations. In addition, appropriate parents and promising crosses were identified by looking at their parents' general combination abilities and specific combination abilities and heterosis values of the crosses. The results obtained were also supported by the principal component analyses. Consequently, the $\mathrm{DH} 22$ line is appropriate for breeding programs for high end-use quality and biofortified capacity. "DH20xHarmankaya", "DH22xHarmankaya", "DH21xAltay" and "DH18xAltay" are promising crosses for biofortification and end-use quality.
\end{abstract}

Keywords: zinc and iron concentration, kernel dimensions, protein rate, color values, gene action, malnutrition

\section{Introduction}

Wheat (Triticum aestivum L.) is one of the cereals with the highest production worldwide and its traits such as easy marketing, transportation, storage and processing facilities encourage wheat cultivation. This intense and unending interest in wheat farming has also intensified plant breeding efforts to make the agricultural characteristics of wheat more suitable to consumer demands. Until today, major improvements in yield, processing and end-use quality of wheat has been obtained with agronomy and plant breeding. Despite this advancement, common food shortages maintain, there are a lot of undernourished people in the world today, predominantly in the developing countries. The changes in the yield potential of today's wheat varieties and the rapidly decreasing genetic potential, which are caused by the changing climatic conditions, make the breeding studies indispensable. Maintaining grain quality besides yield under climate change is critical for human nutrition, end-use functional traits and commercial value of wheat (Nuttall et al., 2017).

Grain quality is defined by a range of physical and compositional characters which are important end-use requirements and commercial value. Physical characteristics of the wheat kernel, including grain weight, dimensions, shape and hardness, influence the classification, milling, transportation, storage and market value of bread wheat (Maphosa et al., 2014). Grain color that can be included in physical quality characters of the kernel is also a frequently used parameter for the classification of wheat and quality 
determination. Market classes of bread wheat are based in part on white or red kernel color. Color is of extensive significance in food preference, and it may be a guarantee of purity and trueness to the preferred type (Graham et al., 1999). The compositional characteristics include protein concentration and composition of other nutrients. Grain protein concentration and composition determine nutritional and end-use characters of dough mixing and rheological traits including loaf volume, dough strength, extensibility, breakdown and development time all of which influence the activity of the bread making process and product quality (Nuttall et al., 2017). Macro and micronutrient elements such as phosphor $(\mathrm{P})$, potassium $(\mathrm{K})$, copper $(\mathrm{Cu})$, iron $(\mathrm{Fe})$ and zinc $(\mathrm{Zn})$ in the other nutrients constituting the grain composition are important components determining grain quality.

Cereal crops which are an important source of minerals and other nutrients for humans supply $44 \%$ of the daily intake of Fe (15\% from bread), $25 \%$ of $\mathrm{Zn}$ (11\% from bread) and $31 \%$ of $\mathrm{Cu}$ (14\% from bread) (Henderson et al., 2003). Especially, high Zn and $\mathrm{Fe}$ concentrations in bread wheat are important quality characters because they could reduce micronutrient malnutrition-related problems in the developing world (Velu et al., 2012). Iron is an necessary element for nearly all alive organisms as it plays a role in a wide diverse of metabolic processes, including haemoglobin formation, deoxyribonucleic acid (DNA) synthesis, oxygen and electron transport (Abbaspour et al., 2014). In addition, $\mathrm{Zn}$ is one of the most important trace elements whose significance to health is increasingly appreciated. It has three major biological roles, as catalyst, structural, and regulatory ion in the organism and its deficiency may play an important role in the appearance of diseases (Chasapis et al., 2012). One of the minerals required for human nutrition is also $\mathrm{Cu}$, which can create negative health effects in case both deficiency and excess (Stern et al., 2007). Potassium is one of the essential nutrients in the human body with the regulatory effect of blood pressure. It is important because of requiring in human nutrition, also it provide increased in quality of edible parts of crops and crop yield (He and MacGregor, 2008). Plant breeding to reduce the extent of mineral nutrient deficiencies and especially increase micronutrient concentrations such as $\mathrm{Fe}$ and $\mathrm{Zn}$ in cereal grain is named genetic biofortification and it is the most sustainable approach and a widely accepted strategy for this aim (Cakmak, 2008).

Grain quality is influenced by genotype, environment and agronomic practise. There is strong genetic control over physical kernel features like shape, thickness and volume just as functional properties of wheat such as grain hardness, protein content and composition (Ferreira et al., 2012). Grain color is also a simply inherited feature and can be easily combined with high-yielding traits (Graham et al., 1999). Over all, the understanding gene action play role in heritability of milling and end-use characteristics will provide a powerful tool for developing breeding strategies for overcoming the effects of climate change to grain quality. Knowing type of gene effect in the formation of a character is important to determine the breeding method to be able to improve the mentioned feature. In addition, improving biofortified wheat varieties which have desirable nutritional quality, protein content, processing quality and higher grain yield will provide reduction for undernourishment and malnutrition at developing countries.

It has been endeavored providing more crop yield and quality alternatives to farmers in developed varieties with conventional breeding. However, nutritional value of crop has been usually disregarded. Present genetic variation, heritability of characters, gene action, relationship among traits, and the availability of diagnostic tools and screening 
techniques are criteria mostly used to define candidate characters and estimate potential genetic gains. Breeding for enhanced micronutrient content should performed basically depend on accompanying agronomic or end-use traits to be adopted by farmers and consumers. The availability of genetic variation for micronutrient density is necessary for determining the applicability of obtaining meaningful enhancement through conventional breeding. If there is adequate genetic variation, breeders can utilize transgressive segregation, additive gene effects and heterosis to develop micronutrient density (Pfeiffer and McClafferty, 2007). When the required genetic variation is not available, combining through hybridization is frequently used by plant breeders to create genetic variation. The breeder would like to recognize the parental and cross offspring in these newly developed cross populations in terms of desired characteristics in early generations and to choose those with superior characteristics. Knowing heritability and type of gene effect in the characters to be transferred, general and specific combination abilities of selected parents is important to determine breeding method and facilitate cultivar development studies. "Line $\mathrm{x}$ tester" analysis is frequently used as an easy and powerful statistical approach for determining combining ability of genotypes in plant breeding (Aslam et al., 2014).

The main purpose of the study was to identify the best parents and promising crosses according to general and specific combining ability of them for physical and chemical quality traits to determine the potential of desirable end-use quality and biofortification properties in bread wheat. In addition, determination of gene effects that play role in inheritance of these traits related to quality and biofortification was aimed.

\section{Materials and methods}

\section{Plant material and experimental design}

In the study, plant materials are seven doubled haploid (DH) wheat lines gained from the $\mathrm{F}_{2}$ generation of hybrids between 33IBSWN-S-244, Tosunbey and Mufitbey, four registered cultivars (Altay 2000, Bezostaja-1, Harmankaya 99, Kate A-1) and twentyeight crosses obtained from them. Hybridization method was line $\mathrm{x}$ tester mating design. The 39 genotypes were grown in randomized complete block design with three replications. The field experiment was conducted at Eskisehir Osmangazi University Agriculture Faculty research areas, Eskisehir, Turkey in 2016-17 growing season. The plots consisted of four rows which are $1 \mathrm{~m}$ long with 20 plants and distance between rows was $30 \mathrm{~cm}$. Standard practices used by the breeding programs were applied as agronomic practices. Wheat grain was harvested at crop maturity and grain samples were analysed in terms of physical and chemical properties.

\section{Physical kernel properties}

Three principal kernel dimensions (length, width and thickness) were measured using a digital caliper (Neiko, 01409A, made in USA) reading to an accuracy of $0.01(\mathrm{~mm})$. Kernel length was accepted as the longest line through the grain, which almost always runs from the embryo to the distal end, and kernel width was the longest line through the grain at a $90^{\circ}$ angle to the length, while kernel thickness was determined the longest line through the grain that is perpendicular to both the length and the width. Then, kernel sphericity (KS) and volume (KV) were calculated using the following equations: 


$$
\begin{gathered}
\mathrm{KS}=\left((\mathrm{LWT})^{1 / 3}\right) / \mathrm{L} * 100 \\
\mathrm{KV}=4 / 3 . \Pi . \mathrm{LWT}
\end{gathered}
$$

(Mohsenin, 1986)

(Weisstein, 2018)

In these equations, L, W, T indicated length, width and thickness, respectively. Kernel hardness (KH) was determined as SKCS hardness index (HI) using the Single Kernel Characterization System 4100 (SKCS) (Perten Instruments, North America, Inc., Springfield, IL, USA). Similarly, kernel weight was measured using a sample of 300 kernels (Method 55-31) and then calculated thousand kernel weights (AACCI, 2000). The hectolitre weight was determined using a $250 \mathrm{ml}$ volume hectolitre scale (Loyka $\mathrm{H}$ Hectolitre scales).

The kernel color of wheat genotypes was determined using Granular Attachment CRA50 with Konica Minolta Chroma Meter CR-400 for each replicate. The CIE (Commission Internationale De L'eclairage) L (lightness), CIE a (red-green) and CIE b (yellow-blue) were read using a D65 light source and the observer angle at $2^{\circ}$. The tristimulus values of CIE $\mathrm{L}, \mathrm{a}$ and $\mathrm{b}$ readings were calibrated against a standard white plate $(\mathrm{Y}=84.8 ; \mathrm{x}=0.3199 ; \mathrm{y}=0.3377)$.

\section{Chemical kernel properties}

Kernel nitrogen $(\mathrm{N})$ content was determined by the Kjeldahl method (Kirk and Sawyer, 1991), and then total protein content (\%) calculated by multiplying the $\mathrm{N}$ percentage by 5.7. The ground samples were turned into ash at $500{ }^{\circ} \mathrm{C}$ in furnace for $5 \mathrm{~h}$ and then dissolved in $3.3 \% \mathrm{HCl}$ and analyzed for $\mathrm{K}, \mathrm{Zn}, \mathrm{Fe}$ and $\mathrm{Cu}$ by using atomic absorption spectrometer (Analytic-Jena novAA 350, Germany) according to Balint et al. (2001). To check the related elemental measurements, reference tomato leaf samples from National Institute of Standards and Technology (Gaithersburg, MD, USA) were used. Phosphorus concentrations of these samples were measured colorimetrically according to the Barton (1948) method. The analysis results were confirmed by NIST Reference Material 8436 Status Wheat Flour.

\section{Statistical analyses}

The analyses of variance, general combining ability (GCA), specific combining ability (SCA), variance of additive and dominant gene effects based on variances of general and specific combination abilities and broad and narrow sense heritability were calculated according to Falconer (1980), using the TarPopGen Statistical Package Program developed by Ozcan (1999). The magnitude of heterosis over mid parent value and over better parent value (heterobeltiosis) was estimated according to the method suggested by Chiang and Smith (1967) and Fonseca and Patterson (1968), respectively.

The raw data of variables into distinct principal factors representing the different proportions of the data variability was transformed with principal component analysis (PCA). Thus, it was provided data reduction and transforming the raw data into principal components. PCA factors were equal to the number of studied variables which were 17 initial in this study, then these factors was transformed the raw data into six factors with the pattern that first factor contributed the most variability. The first six factors have effectively transformed the raw data, extracted significant variability and considerable for further data analysis due to having more than 1.0 eigenvector values. Maximum iterations for convergence were 25; and the variamax rotation method was 
applied. The other factors had eigenvector value less than 1.0 not effective in order to interpret the results. However, evaluation of the first four factors instead of the first six factors resulted in a more meaningful grouping. Bi-plot was drawn by using principal factors, which have most of variability. Bi-plot was two dimensional scatter diagrams which depicted the scattering pattern of genotypes and traits. The maximum, minimum and mean values of genotypes for each trait were shown as box-plot. These analyses carried out with psych" $\mathrm{R}$ package ( $\mathrm{R}$ version 3.3.1).

\section{Results and discussion}

\section{End-use quality of parents and hybrids}

The maximum, minimum and mean values of psychical kernel characteristic for "line $\mathrm{x}$ tester" bread wheat crosses were shown in Figure 1. For all genotypes, values of psychical kernel traits were ranged 5.97-7.12 $\mathrm{mm}$ for kernel length, 2.29-3.15 mm for kernel width, 2.86-3.45 mm for kernel thickness, 163.59-311.52\% for kernel volume, $55.58-61.75 \%$ for kernel spherecity, 31.66-42.36 g for thousand kernel weights and $74.35-81.33 \mathrm{~kg}$ for hectolitre weight. The best parents among the testers were Harmankaya for kernel length while Bezostaja-1 for all psychical kernel traits. Among the lines, DH18 for kernel length, DH19 for kernel hardness and DH6 for hectolitre weight, while DH20 had the best performance for many of psychical kernel traits. Variation of crosses for these traits were quite small and mostly between their parents. "DH6 x Harmankaya", "DH22 x Harmankaya", "DH19 x Altay", "DH19 x Kate" and "DH20 x Bezostaja" were remarkable crosses for these traits (Fig. 1).

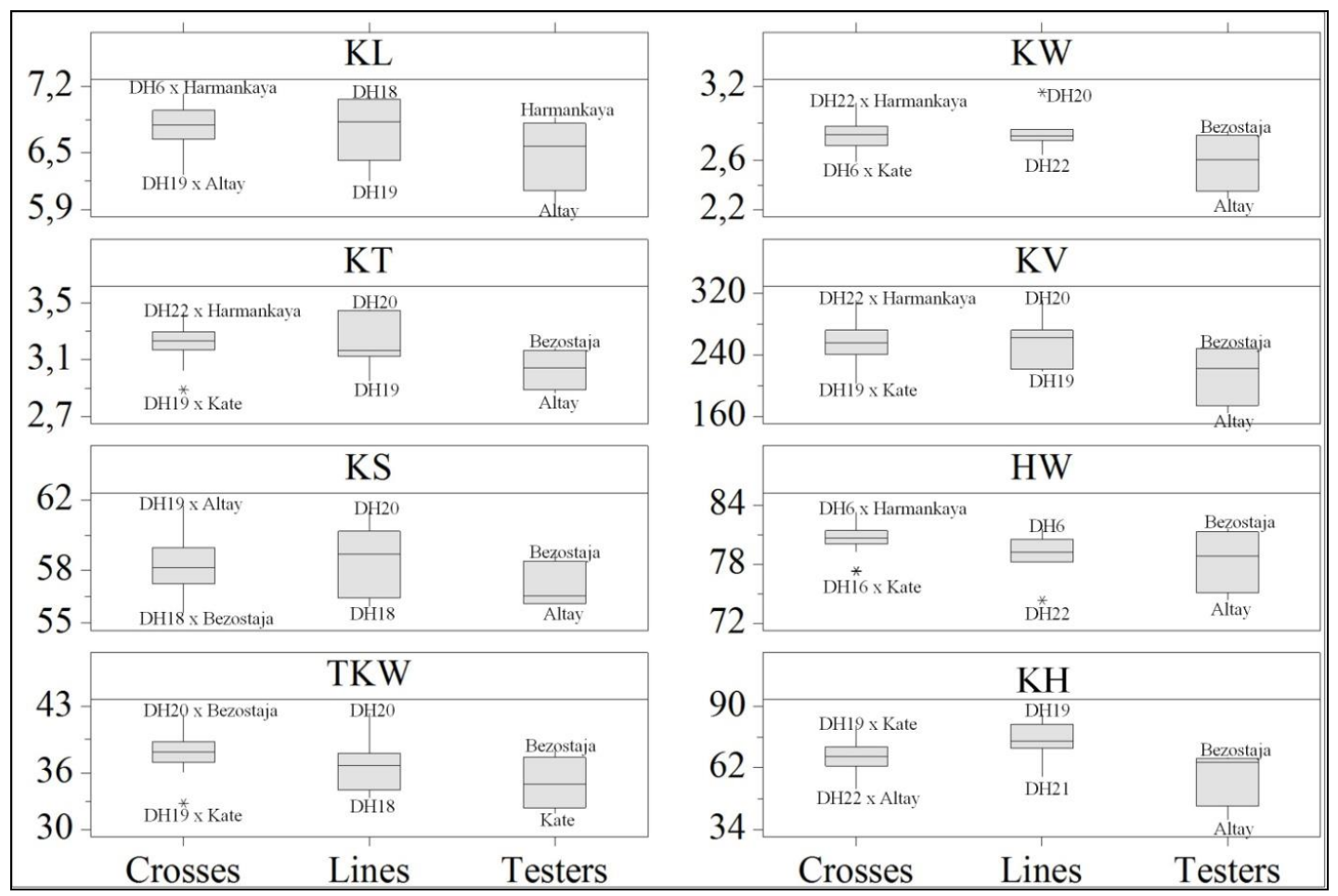

Figure 1. Maximum, minimum and mean values of psychical kernel characteristic for line $x$ tester bread wheat crosses. KL: kernel length ( $\mathrm{mm}), K W$ : kernel width (mm), KT: kernel thickness (mm), KV: kernel volume (\%), KS: kernel sphericity (\%), HW: hectolitre weight (kg), TKW: thousand kernel weight (g), KH: kernel hardness (SKCS-HI) 
Kernel length, width, thickness, sphericity and volume affect the amount of flour. Because can be extracted in milling more flour, it is preferred with large, round and plump grain than small, thin and shrivelled grain (Maphosa et al., 2014). Thousand kernel weights that is an important component of grain yield is one of the physical factors that are indicative of grain size and determines grain quality and it is very important to focus on breeding studies (Korkut et al., 2001). Hectolitre weight is an important physical quality element used in wheat standards. As it increases, the amount of dry matter and flour increase (Schuler et al., 1995). If considered to the observed values, it is thought that the flour yield and milling quality of the mentioned genotypes and therefore the market values may be higher. Kernel hardness, in other words, the texture of wheat, has a great influence on the quality and general processing properties of bread wheat (Ponce-García et al., 2016). Hardness affects milling and if grain is harder, starch content is more damaged. Gas retention capacity, fermentation tolerance, water absorption, energy consumption in the mill increase (Hruskova and Svec, 2009). In the grain hardness measurements made with SKCS, hard wheat scores are around 75 and soft wheat scores 30 and below. According to this, genotypes DH6, DH16, DH19, DH22, "DH6 x Kate", "DH16 x Bezostaja", "DH19 x Harmankaya" and "DH19 x Kate" belong to the hard wheat class.

The L color value of the crosses, lines and tester measured in the kernel ranged from 43.93 to 56.94, with an average of 49.19. The line DH18, the tester Altay and their cross have the highest values $(53.98,56.94$ and 56.73, respectively), it has been the lowest with the "DH21 x Harmankaya", Kate and DH19 (Fig. 2). In terms of a value in kernel, "DH20 x Altay" had the highest value (13.20), while "DH22 x Bezostaja" was the last value with 10.84 and the average of the genotypes was 12.01 . The $b$ value of the kernel was determined as the lowest 20.12 in "DH16 x Bezostaja", while as the highest 26.65 in "DH20 x Altay". The average of genotypes was 22.96 and the all lines were exceeding the average, while only one tester (Altay) exceeded it (Fig. 2).

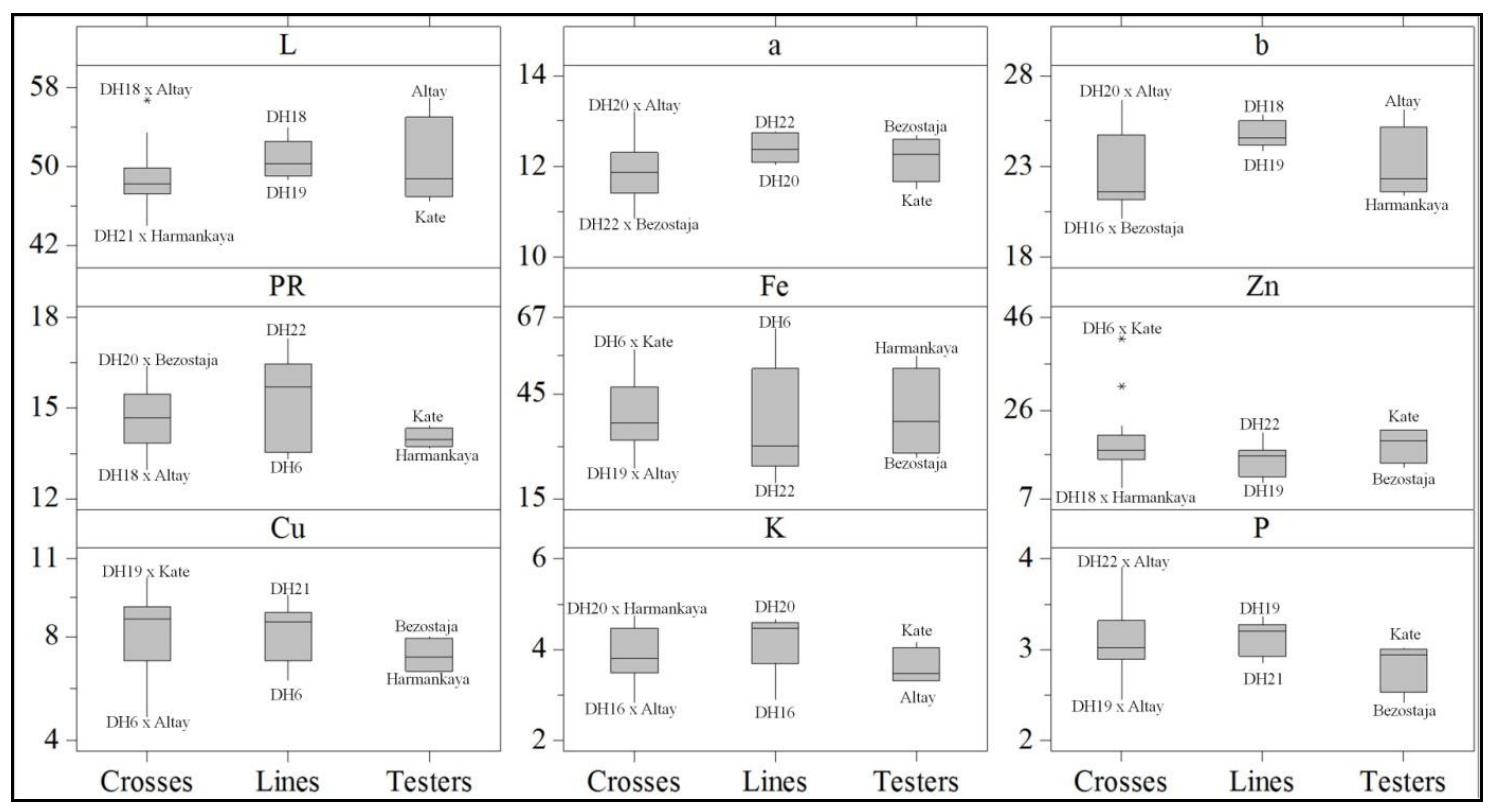

Figure 2. Maximum, minimum and mean values of chemical kernel characteristic for line $x$ tester bread wheat crosses. L: lightness, a: red-green, b: yellow-blue, PR: protein rate (\%), Fe: iron $\left(m g \mathrm{~kg}^{-1}\right), \mathrm{Zn}$ : zinc $\left(m g \mathrm{~kg}^{-1}\right)$, Cu: copper $\left(m g \mathrm{~kg}^{-1}\right)$, K: potassium $\left(m g \mathrm{~kg}^{-1}\right)$, P: phosphorous $\left(m g g^{-1}\right)$ 
Kernel color serves as the basis for segregating wheat grain into classes. Wheat grains have white, yellow and red colors. These color differences are generally are caused by color materials present in different parts of the grain and genotypic differences. The fact that the grain is normal and light indicates that the grain is solid, thin-crusted and soft, and that it is normal and dark color indicates that the grain belongs to the hard wheat variety. When the observation values were examined, it was seen clearly that $\mathrm{L}$ value is low and a value is high for genotypes with high hardness and protein rate. Namely, dark colored and red grained genotypes had harder and higher protein. Although high protein contents and taking a long time pre-harvest sprouting resistance has been associated with red kernel color in wheat, white kernel color in wheat is preferred for the principal foods made from wheat in some countries (De Peuw and McCetc, 1988). Therefore, breeding programs are planned according to consumer demands for wheat kernel color.

\section{Protein and mineral contents of genotypes}

It is desirable that the amount of protein that plays a role in the occurring of wheat quality is least $11 \%$ for bread and $9 \%$ for biscuits. As shown in Figure 2, among parents, the highest protein content $(17.30 \%)$ was found in the DH22 and the lowest protein content $(13.30 \%)$ was detected in the DH6 line. Among the crosses, "DH20 x Bezostaja" had the highest value with $16.38 \%$. McNeal et al. (1965) reported that $\mathrm{F}_{1}$ crosses shown a lower mean value than parents in terms of protein content, while Perenzin et al. (1992) informed that they had higher protein content than their parents. In this study, cross combinations were usually among parental values.

Genetic variation for $\mathrm{Zn}$ and $\mathrm{Fe}$ is quite limited in registered wheat cultivars, so they are not useful for usage in breeding programs (Cakmak et al., 2004; Zhao and McGrath, 2009; Gomez-Becerra et al., 2010). However, the desired genetic diversity can be created by a suitable hybridization program. In this study, Fe (19.40-63.94 mg Fe kg-1) and $\mathrm{Zn}$ (9.29-41.43 $\left.\mathrm{mg} \mathrm{Zn} \mathrm{kg}^{-1}\right)$ had the largest variation among the examined micronutrients. Similar results were found by Gomez-Becerra et al. (2010). The highest Fe concentration was detected in DH6 line, the cross "DH6 x Kate" and tester Harmankaya followed it with 57.91 and $56.05 \mathrm{mg} \mathrm{kg}^{-1}$, respectively. Zinc concentrations varied between 9.29 and 41.43 and mean values was $18.30 \mathrm{mg} \mathrm{kg}^{-1}$. "DH6 x Kate" among the crosses, Kate between the testers and DH22 between the lines were remarkable genotypes (Fig. 2).

Copper concentrations of wheat genotypes ranged from 4.90 to 10.30 and the mean $\mathrm{Cu}$ concentration was $8.04 \mathrm{mg} \mathrm{kg}^{-1}$. The best genotypes were "DH19 x Kate" and $\mathrm{DH} 21$, while the least $\mathrm{Cu}$ concentration was detected "DH6 x Altay". Mean values of K and $\mathrm{P}$ concentrations were around 4.0 and $3.0 \mathrm{mg} \mathrm{kg}^{-1}$ and there were narrow variations among genotypes. The highest $\mathrm{K}$ concentration was found "DH20 x Harmankaya" with $4.75 \mathrm{mg} \mathrm{kg}^{-1}$, while the highest $\mathrm{P}$ concentration was $3.92 \mathrm{mg} \mathrm{kg}^{-1}$ in "DH22 x Altay". DH20 and DH19 were promising parents for high K and P concentrations (Fig. 2).

\section{"Line $x$ tester" variance analyses and estimates of genetic components}

The results of "line $\mathrm{x}$ tester" variance analysis for each character of genotype and cross combinations are given in Table 1. In the analysis of the variance of the traits examined, the squares of all the genotypes (treatment) were found to be significant, while the parents had a statistically significant variation with respect to all other features except the a value. 
Table 1. Line x tester variance analysis for each character of genotype and hybrid combinations

\begin{tabular}{|c|c|c|c|c|c|c|c|c|c|c|c|c|c|c|c|c|c|c|}
\hline VK & DF & $\begin{array}{c}\text { Kernel } \\
\text { length } \\
(\mathbf{m m})\end{array}$ & $\begin{array}{c}\text { Kernel } \\
\text { width } \\
(\mathbf{m m})\end{array}$ & $\begin{array}{c}\text { Kernel } \\
\text { thickness } \\
(\mathbf{m m})\end{array}$ & $\begin{array}{c}\text { Kernel } \\
\text { volume } \\
(\%)\end{array}$ & $\begin{array}{c}\text { Kernel } \\
\text { sphericity } \\
(\%)\end{array}$ & $\begin{array}{c}\text { Kernel } \\
\text { hardness } \\
\text { (HI) }\end{array}$ & $\begin{array}{c}\text { Thousand } \\
\text { kernel } \\
\text { weight (g) }\end{array}$ & $\begin{array}{c}\text { Hectolitre } \\
\text { weight } \\
\text { (kg) }\end{array}$ & $\mathbf{L}$ & $\mathbf{a}$ & b & $\begin{array}{c}\text { Protein } \\
\text { rate } \\
(\%)\end{array}$ & $\begin{array}{c}\mathrm{Fe} \\
\mathrm{mg} \mathrm{kg}^{-1}\end{array}$ & $\begin{array}{c}\mathrm{Zn} \\
\mathrm{mg} \mathrm{kg}^{-1}\end{array}$ & $\begin{array}{c}\mathrm{Cu} \\
\mathrm{mg} \mathrm{kg}^{-1}\end{array}$ & $\begin{array}{c}P \\
\mathrm{mg} \mathrm{kg}^{-1}\end{array}$ & $\begin{array}{c}\mathrm{K} \\
\mathrm{mg} \mathrm{kg}^{-1}\end{array}$ \\
\hline Replication & 2 & $0.00^{\mathrm{ns}}$ & $0.01^{\mathrm{ns}}$ & $0.02^{\mathrm{ns}}$ & $428.27^{\mathrm{ns}}$ & $1.53^{\mathrm{ns}}$ & $10.63^{\mathrm{ns}}$ & $5.06^{\mathrm{ns}}$ & $0.30^{\mathrm{ns}}$ & $2.86^{\mathrm{ns}}$ & $0.16^{\mathrm{ns}}$ & $1.27^{\mathrm{ns}}$ & $0.00^{\mathrm{ns}}$ & $2.6^{\mathrm{ns}}$ & $0.04^{\mathrm{ns}}$ & $0.60^{\mathrm{ns}}$ & $0.04^{\mathrm{ns}}$ & $0.23^{\text {ns }}$ \\
\hline Treatment & 38 & $0.22^{* *}$ & $0.07^{* *}$ & $0.06^{* *}$ & $2659.90^{* *}$ & $7.05^{* *}$ & $245.92^{* * *}$ & $17.26^{* *}$ & $10.73^{* *}$ & $26.04^{* *}$ & $1.03^{* *}$ & $11.72^{* *}$ & $3.35^{* *}$ & $360.09^{* * *}$ & $106.56^{* *}$ & $6.27^{* *}$ & $0.35^{* *}$ & $0.96^{* *}$ \\
\hline Parents & 10 & $0.37^{* *}$ & $0.14^{* *}$ & $0.10^{* *}$ & $4604.31^{* *}$ & $10.45^{* *}$ & $533.50^{* * *}$ & $25.56^{* *}$ & $19.94^{* *}$ & $26.60^{* *}$ & $0.43^{\text {ns }}$ & $7.27^{* *}$ & $5.40^{* *}$ & $640.75^{* *}$ & $49.06^{* *}$ & $3.56^{* *}$ & $0.22^{* *}$ & $1.12^{* * *}$ \\
\hline Interaction & 1 & $0.47^{* * *}$ & $0.12^{* *}$ & $0.14^{* * *}$ & $6361.97^{* *}$ & $0.61^{\mathrm{ns}}$ & $128.50^{\mathrm{ns}}$ & $99.60^{* *}$ & $78.00^{* *}$ & $92.99^{* * *}$ & $3.98^{* *}$ & $60.99^{* * *}$ & $0.44^{* *}$ & $137.41^{* * *}$ & $171.63^{* *}$ & $0.88^{\mathrm{ns}}$ & $0.17^{* *}$ & $0.00^{\mathrm{ns}}$ \\
\hline Crosses & 27 & $0.15^{* *}$ & $0.04^{* *}$ & $0.05^{* *}$ & $1802.63^{* *}$ & $6.03^{* *}$ & $143.76^{*}$ & $11.14^{\mathrm{ns}}$ & $4.83^{* *}$ & $23.35^{* *}$ & $1.14^{* *}$ & $11.54^{* *}$ & $2.70^{* * *}$ & $264.39^{* * *}$ & $125.45^{* *}$ & $7.45^{* *}$ & $0.40^{* *}$ & $0.94^{* *}$ \\
\hline Lines & 6 & $0.28^{*}$ & $0.04^{\mathrm{ns}}$ & $0.06^{\mathrm{ns}}$ & $2054.97^{\mathrm{ns}}$ & $10.10^{* *}$ & $252.14^{* * *}$ & $21.78^{*}$ & $7.60^{\mathrm{ns}}$ & $28.61^{*}$ & $1.42^{* *}$ & $2.49^{\text {ns }}$ & $7.77^{* *}$ & $514.79^{*}$ & $128.76^{\mathrm{ns}}$ & $25.97^{* * *}$ & $0.74^{\mathrm{ns}}$ & $3.68^{* * *}$ \\
\hline Testers & 3 & $0.24^{\mathrm{ns}}$ & $0.11^{*}$ & $0.08^{\mathrm{ns}}$ & $3321.27^{\mathrm{ns}}$ & $20.11^{* *}$ & $581.91^{* *}$ & $18.34^{\mathrm{ns}}$ & $2.93^{\mathrm{ns}}$ & $94.11^{* *}$ & $5.42^{* * *}$ & $85.40^{* *}$ & $0.28^{\mathrm{ns}}$ & $213.58^{\mathrm{ns}}$ & $63.13^{\text {ns }}$ & $1.66^{\mathrm{ns}}$ & $0.23^{\mathrm{ns}}$ & $0.27^{\mathrm{ns}}$ \\
\hline Line $\mathrm{x}$ Tester & 18 & $0.09^{* *}$ & $0.03^{* *}$ & $0.04^{* *}$ & $1465.40^{* *}$ & $2.32^{* *}$ & $34.61^{\mathrm{ns}}$ & $6.39^{\text {ns }}$ & $4.22^{* *}$ & $9.80^{* *}$ & $0.34^{\mathrm{ns}}$ & $2.2^{\mathrm{ns}}$ & $1.41^{* *}$ & $189.39^{* * *}$ & $134.73^{* *}$ & $2.25^{* *}$ & $0.32^{* * *}$ & $0.14^{* *}$ \\
\hline Error & 76 & 0.003 & 0.003 & 0.003 & 53.70 & 0.38 & 85.04 & 7.45 & 1.39 & 4.08 & 0.49 & 1.73 & 0.01 & 0.91 & 2.04 & 1.01 & 0.02 & 0.05 \\
\hline \multicolumn{19}{|l|}{$\mathrm{GC}$} \\
\hline$\sigma^{2} \mathrm{GCA} / \sigma^{2} \mathrm{SCA}$ & & 0.03 & 0 & 0 & 0.02 & 0.13 & -0.08 & -0.30 & 0.01 & 0.16 & -0.03 & 1.20 & 0.06 & 0.03 & -0.01 & 0.28 & 0.2 & 0.58 \\
\hline$\sigma^{2} \mathrm{~A}$ & & 0.003 & 0 & 0 & 14.99 & 0.165 & 4.85 & 0.21 & 0.03 & 0.60 & 0.04 & 0.413 & 0.06 & 3.33 & -0.41 & 0.23 & 0.004 & 0.04 \\
\hline$\sigma^{2} \mathrm{D}$ & & 0.029 & 0.10 & 0.01 & 470.57 & 0.647 & -16.81 & -0.35 & 0.94 & 1.91 & -0.05 & 0.173 & 0.46 & 62.83 & 44.23 & 0.41 & 0.10 & 0.03 \\
\hline $\mathrm{H}^{2}$ & & 0.99 & 0.96 & 0.95 & 0.98 & 0.95 & 0.49 & 0.70 & 0.77 & 0.86 & 0.68 & 0.87 & 0.99 & 0.99 & 0.98 & 0.86 & 0.95 & 0.95 \\
\hline$h^{2}$ & & 0.09 & 0 & 0 & 0.03 & 0.14 & 0.07 & 0.05 & 0.01 & 0.09 & 0.08 & 0.18 & 0.11 & 0.05 & -0.01 & 0.14 & 0.03 & 0.33 \\
\hline CLV (\%) & & 41.73 & 19.68 & 27.80 & 25.33 & 37.22 & 38.97 & 43.46 & 34.97 & 27.23 & 27.68 & 4.80 & 63.98 & 43.27 & 22.81 & 77.42 & 40.68 & 86.86 \\
\hline CTV (\%) & & 18.02 & 28.89 & 18.36 & 20.47 & 37.07 & 44.97 & 18.30 & 6.74 & 44.78 & 52.66 & 82.22 & 1.15 & 8.98 & 5.59 & 2.47 & 6.45 & 3.16 \\
\hline CLxTV (\%) & & 40.24 & 51.42 & 53.84 & 54.19 & 25.70 & 16.05 & 38.24 & 58.29 & 27.99 & 19.66 & 12.98 & 34.87 & 47.76 & 71.60 & 20.11 & 52.86 & 9.97 \\
\hline
\end{tabular}

$* \mathrm{p} \leq 0.05, * * \mathrm{p} \leq 0.01$. GCA: general combining ability; SCA: specific combining ability, ${ }^{2}$ A: additive gene variance, $\sigma^{2} \mathrm{D}$ : dominance gene variance, $\mathrm{H}^{2}$ : broad sense heritability, $\mathrm{h}^{2}$ : narrow sense heritability, CLV: contribution of lines to variance, CTV: contribution of testers to variance, CLV: contribution of lines $\mathrm{x}$ testers interaction to variance

APPLIED ECOLOGY AND ENVIRONMENTAL RESEARCH 16(5):7305-7326.

http://www.aloki.hu • ISSN 15891623 (Print) • ISSN 17850037 (Online)

DOI: http://dx.doi.org/10.15666/aeer/1605_73057326

○ 2018, ALÖKI Kft., Budapest, Hungary 
When considering at the mean squares of the crosses; there were statistically significant differences according to 5\% level of importance of kernel hardness and $1 \%$ of importance for other properties while thousand kernel weights was non-significant. Among the varieties used as a line, level of $1 \%$ statistically significant differences were found for kernel sphericity, kernel hardness, a value, protein ratio, $\mathrm{Cu}$ and $\mathrm{K}$ concentrations; and level of significant was 5\% for kernel length, thousand kernel weight, L value and Fe concentration. Among the varieties used as tester, kernel width, kernel sphericity, kernel hardness and color values statistically significant variation was found. Among the variances belonging to the "line $\mathrm{x}$ tester" interaction, significant differences were found with respect to all examined traits except for kernel hardness, thousand kernel weight, $a$ and $b$ values.

When the proportional relations of the general and specific combination ability variance estimates of the examined properties and the variance components of the additive and dominance are examined, dominant gene effects were dominated in inheritance of $b$ values; while "additive $x$ dominant" gene interaction were prominent in inheritance of kernel hardness, thousand kernel weight, a value and $\mathrm{Zn}$ concentration. The selection efficiency is concerned with the magnitude of narrow sense heritability in the segregating populations. It was found very low narrow sense heritability degrees for the characters examined in the study (Table 1). This situation indicated that there is very low additive variance in this population and the selection should be postponed to further generations.

Previous researchers (Khan et al., 2010; Istipliler et al., 2015; Kumar et al., 2017) who have detected low narrow sense heritability and dominant gene effects for features such as thousand kernel weight, hectolitre weight, kernel hardness and protein rate, have indicated that the waiting of future generations for selection would be appropriate. Lines, testers, and "line x tester" interaction contributed to combinations' variances was found highly different in examined traits. The contributions of the lines to kernel sphericity, thousand kernel weight, protein rate, $\mathrm{Cu}$ and $\mathrm{K}$ concentrations were defined as highest, while to kernel length and Fe concentration were found closer to "line $\mathrm{x}$ tester" interaction. The contributions of testers were found in highest kernel hardness and color values. It is remarkable that there was much more variation in traits which had the highest "line $\mathrm{x}$ tester" interactions such as kernel width, kernel thickness, kernel volume, hectolitre weight, $\mathrm{Zn}$ and $\mathrm{P}$ concentrations.

\section{General combining abilities of parents}

General combining ability effects of the lines, testers or individual line performances are useful tools for selecting the cross parents in cross pollinated plants. GCA effects of the lines and testers used in the research can be seen at Table 2 for observed traits. The negative GCA effects were generally observed for kernel dimensions. Genotypes DH22 and Harmankaya showed a positive and significant GCA for all kernel dimensions traits, while genotypes DH19 and Kate had negative and significant GCA effects. This situation showed that in the combinations which include these two genotypes had relatively small kernels. All parents had significant GCA effects for kernel volume. However, it can be realized that positive and significant GCA effects increasing the kernel volume are more than negative GCA effects. The DH22, which had the highest positive and significant GCA effect, increased the kernel volume in the combinations in which it took a place (Table 2). Therefore, the line Harmankaya and the tester DH22 were the most suitable parents for increasing this trait due to their high GCA effects. 
Table 2. General combining ability of parents used as lines and testers

\begin{tabular}{|c|c|c|c|c|c|c|c|c|c|c|c|c|c|c|c|c|c|}
\hline Lines & $\begin{array}{l}\text { Kernel } \\
\text { length } \\
(\mathbf{m m})\end{array}$ & $\begin{array}{c}\text { Kernel } \\
\text { width } \\
(\mathbf{m m})\end{array}$ & $\begin{array}{c}\text { Kernel } \\
\text { thickness } \\
(\mathbf{m m})\end{array}$ & $\begin{array}{c}\text { Kernel } \\
\text { volume } \\
(\%)\end{array}$ & $\begin{array}{c}\text { Kernel } \\
\text { sphericity } \\
(\%)\end{array}$ & $\begin{array}{c}\text { Kernel } \\
\text { hardness } \\
\text { (HI) }\end{array}$ & $\begin{array}{l}\text { Thousand } \\
\text { kernel } \\
\text { weight (g) }\end{array}$ & $\begin{array}{c}\text { Hectolitre } \\
\text { weight } \\
\text { (kg) }\end{array}$ & $\mathbf{L}$ & $\mathbf{a}$ & b & $\begin{array}{c}\text { Protein } \\
\text { rate } \\
(\%)\end{array}$ & $\begin{array}{c}\mathrm{Fe} \\
\mathrm{mg} \mathrm{kg}^{-1}\end{array}$ & $\underset{\mathrm{Zg} \mathrm{kg}^{-1}}{\mathrm{Zn}}$ & $\underset{\mathrm{mg} \mathrm{kg}^{-1}}{\mathrm{Cu}}$ & $\begin{array}{c}P \\
\mathrm{mg} \mathrm{kg}^{-1}\end{array}$ & $\begin{array}{c}\mathrm{K} \\
\mathrm{mg} \mathrm{kg}^{-1}\end{array}$ \\
\hline DH6 & 0.02 & 0.01 & $0.07^{* *}$ & $7.21^{* *}$ & 0.30 & 1.48 & -0.36 & $0.89^{*}$ & -0.97 & -0.22 & -0.52 & $-0.66^{* *}$ & $11.60^{* *}$ & $2.41^{* *}$ & $-2.98^{* *}$ & $-0.20^{* * *}$ & $-0.30^{* * *}$ \\
\hline DH16 & -0.01 & $-0.04^{* *}$ & -0.02 & $-6.32^{* *}$ & $-0.39^{*}$ & 1.61 & 0.45 & $-1.29^{* *}$ & 0.72 & -0.39 & -0.71 & 0.00 & $6.30^{* *}$ & $0.98^{*}$ & -0.28 & -0.05 & $-0.69^{* *}$ \\
\hline DH18 & $0.09^{* *}$ & $-0.06^{* *}$ & $-0.04^{* *}$ & $-6.52^{* *}$ & $-1.24^{* *}$ & -5.13 & 1.09 & $1.01^{* *}$ & $2.71^{* *}$ & -0.21 & 0.33 & $-1.27^{* *}$ & $-2.72^{* *}$ & $-4.97^{* *}$ & $0.86^{* *}$ & $-0.24^{* *}$ & $-0.47^{* *}$ \\
\hline DH19 & $-0.28^{* *}$ & $-0.06^{* *}$ & $-0.10^{* *}$ & $-23.33^{* *}$ & $0.65^{* *}$ & $8.27^{* *}$ & $-2.15^{* *}$ & -0.34 & 0.87 & 0.16 & -0.12 & $-0.15^{* *}$ & $-4.94^{* *}$ & $3.20^{* * *}$ & -0.16 & $-0.08^{*}$ & $-0.24^{* *}$ \\
\hline DH20 & $-0.09^{* *}$ & $0.05^{* *}$ & $0.05^{* *}$ & $5.29^{*}$ & $1.19^{* * *}$ & -0.81 & 1.27 & -0.42 & -0.34 & 0.33 & 0.35 & $1.08^{* *}$ & $-6.69^{* *}$ & $-3.70^{* *}$ & 0.05 & 0.02 & $0.45^{* *}$ \\
\hline DH21 & $0.19^{* *}$ & $0.04^{*}$ & $-0.04^{*}$ & $7.33^{* *}$ & $-1.06^{* *}$ & -0.32 & -1.39 & 0.04 & $-1.77^{* *}$ & $0.54^{* *}$ & 0.28 & $0.23^{* *}$ & $-1.40^{* *}$ & -0.80 & $1.04^{* *}$ & 0.06 & $0.62^{* *}$ \\
\hline DH22 & $0.08^{* *}$ & $0.07^{* *}$ & $0.08^{* *}$ & $16.34^{* *}$ & $0.54^{* *}$ & -5.09 & 1.10 & 0.11 & $-1.22^{*}$ & -0.21 & 0.39 & $0.77^{* *}$ & $-2.15^{* *}$ & $2.88^{* * *}$ & $1.47^{* * *}$ & $0.50^{* *}$ & $0.63^{* *}$ \\
\hline SE & 0.02 & 0.01 & 0.02 & 2.12 & 0.18 & 2.66 & 0.79 & 0.34 & 0.58 & 0.20 & 0.38 & 0.04 & 0.28 & 0.41 & 0.29 & 0.04 & 0.06 \\
\hline \multicolumn{18}{|l|}{ Testers } \\
\hline Altay & $-0.11^{* *}$ & $0.07^{* *}$ & $0.04^{* *}$ & $4.45^{* *}$ & $1.37^{* *}$ & $-7.32^{* *}$ & 0.06 & -0.17 & $3.16^{* *}$ & $0.72^{* *}$ & $2.97^{* *}$ & $-0.07^{*}$ & $-4.17^{* *}$ & $-1.03^{* *}$ & -0.35 & $-0.09^{* *}$ & -0.00 \\
\hline Bezostaja-1 & $-0.01^{*}$ & -0.01 & $-0.03^{*}$ & $-4.19^{*}$ & -0.24 & 2.95 & -0.14 & 0.01 & -0.80 & $-0.47^{* *}$ & $-1.34^{* *}$ & 0.03 & $0.57^{* *}$ & $-0.74^{*}$ & 0.18 & -0.04 & $-0.15^{* *}$ \\
\hline Harmankaya & $0.14^{* *}$ & $0.04^{* * *}$ & $0.06^{* *}$ & $14.65^{* *}$ & -0.18 & -0.18 & 1.18 & $0.51^{*}$ & $-1.22^{* * *}$ & -0.10 & $-1.17^{* *}$ & $-0.11^{* *}$ & 0.03 & $-0.83^{* *}$ & -0.09 & -0.02 & 0.03 \\
\hline Kate A-1 & $-0.02^{* *}$ & $-0.09^{* *}$ & $-0.07^{* *}$ & $-14.91^{* *}$ & $-0.95^{* *}$ & $4.56^{*}$ & -1.10 & -0.35 & $-1.14^{*}$ & -0.14 & -0.46 & $0.15^{* *}$ & $3.57^{* *}$ & $2.59^{* * *}$ & 0.26 & $0.15^{* *}$ & $0.12^{\text {** }}$ \\
\hline SE & 0.01 & 0.01 & 0.01 & 1.60 & 0.13 & 2.01 & 0.60 & 0.26 & 0.44 & 0.15 & 0.29 & 0.03 & 0.21 & 0.31 & 0.22 & 0.03 & 0.05 \\
\hline
\end{tabular}

$* \mathrm{p} \leq 0.05, * * \mathrm{p} \leq 0.01$. SE: standard error 
GCA effects of kernel sphericity ranged from -1.24 to 1.37. The negative and significant was observed four parents while three parents had positive and significant GCA effects. When the GCA of parents were examined in terms of kernel hardness value, DH19 and Kate showed positive and significant GCA effect at 1\% and 5\% level, while Altay showed negative and significant GCA effect at $1 \%$ level. GCA effect of other parents was found to be insignificant. Negligible positive and negative effects were observed between lines and testers for thousand kernel weight. Besides, it can be seen that one of the lines called DH19 had negative and significant GCA effect for thousand kernel weight. The GCA effect, which reflects the additive gene effect, was found to be positive and significant in the DH6 and DH18 genotypes among the lines and in the Harmankaya variety as a tester, while the negative and significant GCA effect was observed in the DH16 line for hectolitre weight (Table 2). DH6, DH22 and Harmankaya genotypes having positive GCA effect on all of these properties are potential to be used as parents in breeding studies to improve flour yield and milling quality of bread wheat. For the L value affecting the lightness or darkness of grain color, the GCA effects were generally negative. Combinations of DH18 and Altay parents showing a positive and significant GCA value may be expected to be darker. The GCA values for a value, a indicator for red color, ranged from -0.47 to 0.72 . Bezostaja had negative values, while two of the three parent significant GCA effects were found a positive value. None of the lines for $b$ value had significant GCA effect, whereas three of the tester showed significant positive and negative GCA effect (Table 2). It would be appropriate to use DH21 to obtain darker and red kernels, and to use the Altay genotypes as a parent for light colored and white kernels.

When GCA values for protein rate are examined, it was seen that four parents have a positive, five parents have a negative GCA value and the DH20 had the highest GCA effect. While the lowest GCA effect was obtained from the DH18, the effect of the DH16 was calculated to be zero (Table 2). It can be concluded that parents with a positive GCA effect have the potential to increase the protein rate and transfer these characteristics to future generations. GCA values calculated for $\mathrm{Fe}$ and $\mathrm{Zn}$ contents were found statistically significant in almost all of the parents. DH18, DH20, DH21 and Altay genotypes showing a negative GCA value in terms of Fe content also had a negative value for $\mathrm{Zn}$ content. While DH6, DH16 and Kate with positive GCA values for both Fe and Zn contents may be suitable parents to improve these properties, DH19 and DH22 have the potential to increase $\mathrm{Zn}$ content and Bezostaja has the potential to be suitable parents for breeding programs to increase $\mathrm{Fe}$ content. Three of the four lines that detected the significant GCA effect for $\mathrm{Cu}$ content had a positive value, indicating that they had a $\mathrm{Cu}$ content enhancing effect. Among the parents with important GCA effect for P and K, DH22 and Kate had positive values for both elements (Table 2). Parent Kate was a good combiner for protein rate and biofortified crops indicating that this genotype could be the best candidate as one of the parental lines to improve any of these features.

\section{Specific combining abilities and heterosis values of hybrids}

Although specific combining ability (SCA) is generally suggested for cross pollinated species such as corn or rye (Longin et al., 2013; Istipliler et al., 2015), SCA effects can be used to select homozygous lines that show transgressive segregation. Significant SCA, heterosis and heterobeltiosis values of physical kernel properties were determined both positive and negative (Table 3). This condition indicates that the presence of adequate variation in this population and this cross population contains suitable materials that can be used in breeding studies. 
Table 3. Specific combining ability, heterosis and heterobeltiosis values of crosses for physical kernel properties

\begin{tabular}{|c|c|c|c|c|c|c|c|c|c|c|c|c|c|c|c|c|c|c|}
\hline \multirow{2}{*}{ Crosses } & \multicolumn{3}{|c|}{ Kernel length (mm) } & \multicolumn{3}{|c|}{ Kernel width (mm) } & \multicolumn{3}{|c|}{ Kernel thickness (mm) } & \multicolumn{3}{|c|}{ Kernel volume (\%) } & \multicolumn{3}{|c|}{ Kernel sphericity (\%) } & \multicolumn{3}{|c|}{ Kernel hardness (HI) } \\
\hline & SCA & HT & HB & SCA & HT & \begin{tabular}{|l|} 
HB \\
\end{tabular} & SCA & HT & HB & SCA & HT & HB & SCA & HT & HB & SCA & HT & HB \\
\hline H6 x Altay & & $5.76^{* *}$ & -0.90 & & $19.23^{* * *}$ & & & & & $20.65^{* *}$ & $33.04^{* *}$ & $6.52^{* * *}$ & $.80^{*}$ & & & 0.32 & -2.85 & 29.00 \\
\hline H6 x Bezostaja & -0.02 & 0.65 & -0.85 & 0.02 & -0.69 & & & & $-6.78^{* *}$ & -7.20 & $-3.01^{* * *}$ & $-6.89^{* *}$ & -0.26 & & $-1.76^{*}$ & 34 & -5.47 & -17.25 \\
\hline DH6 x Harm & & & & 0.03 & & & 0.03 & & & & & & -0.60 & & & -1.10 & & \\
\hline DH6 x Kate & & $-1.92^{* *}$ & $-4.18^{* *}$ & $-0.14^{* * *}$ & $-2.15^{* *}$ & $-6.38^{* *}$ & -0.05 & -1.19 & $-8.13^{* *}$ & $-25.60^{* *}$ & $-5.78^{* * *}$ & $-17.60^{* *}$ & 0.06 & 0.25 & $-2.16^{*}$ & 1.08 & -1.71 & -14.52 \\
\hline DH16 x Altay & & $4.31^{* *}$ & -0.31 & 0.01 & & & -0.04 & & 0.02 & -6.91 & & 2.84 & 0.58 & & 1.25 & 4.34 & 9.78 & $-19.06^{*}$ \\
\hline $\mathrm{DH} 16 \times \mathrm{Be}$ & & & $5.25^{* *}$ & $0.17^{* *}$ & & & & & & $32.24^{* *}$ & $13.47^{* *}$ & $11.56^{* *}$ & & & -1.47 & 2.91 & & -8.12 \\
\hline DH16 x Ha & & $1.16^{* *}$ & $-1.26^{*}$ & $-0.13^{* *}$ & & -2.95 & -0.04 & & 0.94 & $-20.19^{* *}$ & 1.69 & 1.57 & -0.41 & -0.65 & $-3.06^{* *}$ & -4.35 & $-13.49^{* * *}$ & $-20.97^{*}$ \\
\hline $\mathrm{H} 16$ & & $3.91^{* *}$ & $3.64^{* *}$ & .05 & & $-5.22^{* *}$ & -0 . & & $-2.67^{*}$ & -5.14 & $3.72^{* * *}$ & -4.43 & $-0.76^{*}$ & $-2.50^{* *}$ & $-4.96^{* *}$ & -2.90 & & \\
\hline DH18 & $0.09^{* *}$ & $4.78^{* *}$ & $-3.59^{* *}$ & 0.03 & 11. & 1.62 & $0.08^{* *}$ & $9.66^{* *}$ & $4.52^{* *}$ & $13.34^{* *}$ & $26.16^{* *}$ & 2.40 & 0.12 & & $2.83^{* *}$ & -1.90 & -4. & \\
\hline $\mathrm{DH} 18 \times \mathrm{B}$ & 0.05 & $0.69^{*}$ & $-2.70^{* *}$ & -0.02 & & $-4.51^{* *}$ & & $-4.62^{* *}$ & -4.9 & $-9.46^{*}$ & & $-9.58^{* *}$ & & & $-5.90^{* *}$ & 0.90 & -3 & -8.02 \\
\hline DH18 x I & $-0.13^{* *}$ & & & & & & & & & $-9.59^{*}$ & & -2.45 & & & $1.91^{*}$ & -2.18 & -14 . & -16.73 \\
\hline DH18x & -0.01 & 0.29 & $-3.88^{* *}$ & 0.03 & 0.99 & $-3.98^{*}$ & 0.04 & $2.96^{* *}$ & -0.1 & 5.72 & $3.70^{* *}$ & $-7.88^{* * *}$ & 0.59 & & 0.99 & 3.18 & 2. & -2.55 \\
\hline H19 & & & & 0.01 & & & $0.11^{* *}$ & $12.46^{* *}$ & 10.7 & 3.9 & 27. & 11.1 & 1.5 & & 2.4 & 3.08 & & \\
\hline DH19 x B & -0.04 & 0.55 & $-2.66^{* *}$ & -0.06 & $-5.73^{* *}$ & $-5.92^{* *}$ & -0.04 & -0.62 & & $-9.56^{*}$ & $-5.90^{* *}$ & -11.9 & -0. & $-2.52^{* *}$ & $-3.49^{* *}$ & -6.47 & -2 & -12.80 \\
\hline $\mathrm{H} 19 \times \mathrm{H}$ & $0.25^{* *}$ & $5.27^{* *}$ & & 0.0 & & & & & 5.1 & 22.3 & 18.0 & 12.4 & & & & & 2. & -7.00 \\
\hline H19 x Kate & & & $-2.21^{* *}$ & & $-2.00^{*}$ & $-7.67^{* *}$ & & & -2.67 & $-16.73^{* *}$ & $-4.02^{* * *}$ & -7.19 & & & & 1.97 & $11.78^{*}$ & -0.55 \\
\hline $\mathrm{H} 20$ x Altay & $15^{* *}$ & 0.22 & $-6.25^{* *}$ & $-0.15^{* *}$ & $2.23^{* *}$ & $-11.80^{* *}$ & $-0.11^{* *}$ & $1.53^{*}$ & $-7.06^{* *}$ & $-27.84^{* *}$ & 0.77 & $-23.16^{* * *}$ & $-0.80^{*}$ & & $-2.30^{* * *}$ & -2.62 & 0.21 & $-23.75^{* *}$ \\
\hline $\mathrm{H} 2 \mathrm{x}_{\mathrm{x}}$ & & -0.34 & $-2.01^{* *}$ & & $-4.54^{* *}$ & $-9.30^{* *}$ & & & -3.5 & $8.62^{*}$ & $-4.87^{* *}$ & -14.2 & 0.36 & $-1.15^{* *}$ & -3.0 & 0.83 & 0.79 & -5.08 \\
\hline $\mathrm{H} 20 \mathrm{x}$ & $0.09^{* *}$ & $0.85^{*}$ & 0.67 & 0.02 & 0.09 & $-7.32^{* *}$ & $0.07^{*}$ & $3.91^{* *}$ & -0.99 & $11.32^{* *}$ & $4.48^{* *}$ & $-7.31^{* *}$ & 0.03 & 0.80 & $-3.48^{* *}$ & 5.58 & 1.73 & -2.87 \\
\hline $\mathrm{H} 20 \mathrm{x}$ & & 0.11 & $-2.37^{* *}$ & $0.12^{* *}$ & & $-8.59^{* *}$ & -0.04 & & -8.0 & 7.90 & -0.74 & $-17.90^{* * *}$ & 0.41 & 0.25 & -4.1 & -3.79 & -2 & -9.17 \\
\hline $\mathrm{H} 21$ x Altay & $0.18^{* *}$ & $8.04^{* *}$ & -0.35 & $0.08^{* *}$ & $17.13^{* *}$ & $5.83^{* *}$ & 0.03 & $7.84^{* *}$ & $2.67^{*}$ & $17.97^{* *}$ & $33.92^{* *}$ & $8.23^{* *}$ & -0.36 & $2.67^{* *}$ & $2.28^{*}$ & -0.42 & $22.02^{* *}$ & 1.42 \\
\hline DH21 x Bezosta & -0.01 & $1.65^{* *}$ & $-1.53^{*}$ & -0.03 & -1.22 & -1.29 & 0.05 & 1.20 & & 1.34 & & -1.29 & 0.17 & $-1.15^{* *}$ & $-3.34^{* *}$ & -1.05 & $11.32^{*}$ & 5.30 \\
\hline $\mathrm{DH} 21 \times \mathrm{H}$ & & & $-3.80^{* *}$ & $-0.11^{* *}$ & & & & & & $-39.06^{* *}$ & & $-9.41^{* *}$ & & & & -0.58 & & -1.70 \\
\hline $\mathrm{H} 21$ x Kate & $0.14^{* *}$ & $4.32^{* *}$ & 0.25 & & $4.78^{* *}$ & -1.04 & $0.13^{* *}$ & $5.77^{* *}$ & 2.46 & $19.75^{* *}$ & $14.94^{* *}$ & 1.61 & 0.40 & 0.63 & 0.31 & 2.05 & $19.96^{* *}$ & 14.30 \\
\hline $\mathrm{H} 22 \mathrm{x}$ Altay & & $9.29^{* *}$ & $5.44^{* *}$ & $-0.11^{* * *}$ & $14.99^{* *}$ & $7.27^{* *}$ & $-0.14^{* *}$ & $6.99^{* *}$ & 2.52 & $-21.12^{* *}$ & $33.48^{* *}$ & $57.19^{* *}$ & $-1.84^{* *}$ & $1.06^{*}$ & -0.36 & -2.15 & -7.31 & $-29.74^{* *}$ \\
\hline $\mathrm{H} 22$ x Bezost & $-0.22^{* *}$ & $1.56^{* *}$ & 0.00 & -0.05 & $2.59^{* *}$ & -0.94 & -0.02 & $3.28^{* *}$ & 2.33 & $-15.98^{* *}$ & $7.48^{* *}$ & 1.35 & $0.80^{*}$ & $0.91^{*}$ & 0.45 & 2.54 & -3.51 & -9.62 \\
\hline DH22 x Harn & 0.06 & $6.12^{* *}$ & $2.60^{* *}$ & $0.15^{* *}$ & $15.33^{* *}$ & $14.40^{* *}$ & & $9.96^{* *}$ & $10.00^{* *}$ & $23.00^{* *}$ & $34.57^{* *}$ & $29.12^{* *}$ & $1.05^{* *}$ & $3.98^{* *}$ & $1.92^{*}$ & 1.21 & $-11.14^{*}$ & -15.62 \\
\hline $\mathrm{DH} 22 \times$ Kate & $0.14^{* *}$ & $7.70^{* *}$ & $6.93^{* *}$ & 0.01 & $8.46^{* *}$ & $5.93^{* *}$ & $0.11^{* *}$ & $9.88^{* *}$ & $7.15^{* *}$ & $14.10^{* *}$ & $28.32^{* *}$ & $23.14^{* *}$ & -0.01 & $0.91^{*}$ & -1.19 & -1.59 & -6.45 & -13.00 \\
\hline SE (SCA) & 0.03 & & & 0.03 & & & 0.03 & & & 4.23 & & & 0.36 & & & 5.32 & & \\
\hline
\end{tabular}

${ }^{*} \mathrm{p} \leq 0.05,{ }^{* *} \mathrm{p} \leq 0.01$. SCA: specific combining ability, HT: heterosis, HB: heterobeltiosis, SE: standard error 
The highest SCA values for kernel length, width, thickness, volume, sphericity and hardness were determined as 0.25 (DH19 x Harmankaya), 0.17 (DH16 x Bezostaja), 0.13 (DH21 x Kate), 32.24 (DH16 x Bezostaja), 1.50 (DH19 x Altay), 5.58 (DH20 x Harmankaya), respectively. Most of the cross combinations for these traits had a positive heterosis value indicating the presence of dominance in the direction of increasing these traits, while most heterobeltiosis values were negative. The heterosis express as percent deviation of cross from its mid-parental value, whereas heterobeltiosis was as percent superiority of cross in comparison to the best parent. Therefore, effective selection of desirable recombinants from crosses with significant high heterobeltiosis value is more likely to be. "DH22 x Kate" for kernel length, "DH22 x Harmankaya" for kernel width, "DH19 x Altay" for kernel thickness, "DH22 x Altay" for kernel volume, "DH6 x Altay" for kernel sphericity and "DH21 x Kate" for kernel hardness had the highest and desirable heterobeltiosis value. It was observed that "DH16 x Bezostaja", "DH20 x Harmankaya" and "DH21 x Kate" combinations had positive and significant SCA effects for all physical kernel properties (Table 3). Besides that, these combinations had the positive heterosis and heterobeltiosis values. Kernel size, volume, sphericity and hardness provide important information about flour yield. It was determined that the flour yield of large sized and hard kernel was higher and that the amount of grain protein was not decreased during milling (Dziki and Laskowski, 2005). In parents and crosses, those with positive and significant combination abilities, heterosis and heterobeltiosis values can be recommended for use in breeding studies to increase of kernel size, hardness and therefore to increase yield of flour.

"DH6 x Harmankaya", "DH18 x Altay" and "DH22 x Kate" crosses, which have a high SCA effect value, can be pursued for a thousand kernel weight, although all crosses have non-significant SCA effect. The heterosis values of the crosses for thousand kernel weight ranged from $-4.02 \%$ (DH6 x Bezostaja) to $21.44 \%$ (DH18 x Altay) and the number of positive and significant heterosis value was detected thirteen. Four of the significant heterobeltiosis crosses were positive (Table 4). The highest heterobeltiosis was determined in the "DH18 x Altay" cross, followed in "DH18 x Harmankaya". Crosses showing positive heterobeltiosis can be considered as promising because heterobeltiosis is an indication of a performance exceeding both parents. For the hectolitre weight, the SCA effects of crosses varied between -1.80 (DH16 x Altay) and 1.89 (DH16 x Bezostaja). Half of the crosses showed a negative SCA effect while the other half showed a positive SCA effect. Only the DH16 cross series had statistically significant SCA effect. Two of the crosses (DH16 x Altay and DH16 x Kate) were found to be significant negative and the other two positive. When the heterosis values of the crosses were examined, significant values were calculated for $5 \%$ negative in a cross, $1 \%$ negative in a cross, and non-significant values in six crosses. All other crosses showed positive and significant heterosis. The heterobeltiosis values of the crosses were found to be statistically insignificant, and "DH22 x Altay" and "DH22 x Kate" combinations showed a positive significant value (Table 4). When the SCA values and heterosis-heterobeltiosis values of the crosses are considered together; the combination of "DH16 x Altay", "DH18 x Altay", "DH19 x Harmankaya", "DH20 x Kate" and "DH21 x Kate" should be followed as promising crosses in order to increase the hectolitre weight. Since, hectolitre weight and thousand kernel weight are one of the indicators of flour yield (Pomeranz, 1964); the wheat genotypes which have high thousand kernel weight and hectolitre weight are preferred in the flour industry. Hence "DH6 x Harmankaya", "DH18 x Altay", "DH19 x Altay", "DH19 x Harmankaya" and "DH22 x Kate" combinations are preferable for flour industry with their positive SCA, heterosis and heterobeltiosis values for both thousand kernel weight and hectolitre weight. 
Table 4. Specific combining ability, heterosis and heterobeltiosis values of crosses for thousand kernel weight, hectolitre weight and color values

\begin{tabular}{|c|c|c|c|c|c|c|c|c|c|c|c|c|c|c|c|}
\hline \multirow{2}{*}{ Crosses } & \multicolumn{3}{|c|}{ Thousand kernel weight (g) } & \multicolumn{3}{|c|}{ Hectolitre weight (kg) } & \multicolumn{3}{|c|}{$\mathbf{L}$} & & \multicolumn{3}{|c|}{ b } \\
\hline & SCA & HT & HB & SCA & HT & HB & SCA & \begin{tabular}{|l|} 
HT \\
\end{tabular} & HB & SCA & HT & HB & SCA & HT & HB \\
\hline DH6 x Altay & -0.12 & $6.71^{*}$ & 2.83 & 0.57 & 5.02 & 0.29 & $-3.15^{* *}$ & $-11.03^{* *}$ & $-16.26^{* *}$ & -0.24 & -2.20 & -3.01 & 0.04 & -0.51 & -4.29 \\
\hline DH6 x Bezostaja & -1.70 & -4.02 & -5.95 & -1.19 & -1.63 & -1.64 & 0.64 & $-4.29^{*}$ & -5.43 & 0.16 & $-9.88^{* *}$ & $-10.48^{*}$ & 0.47 & $-8.96^{* *}$ & $-12.51^{* *}$ \\
\hline DH6 x Harmankaya & 1.50 & $12.14^{* *}$ & 10.27 & 1.27 & 2.88 & 1.98 & 1.43 & -0.96 & -4.72 & 0.51 & -2.21 & -3.54 & 0.52 & $-6.14^{*}$ & $-11.60^{*}$ \\
\hline DH6 x Kate & 0.32 & 8.43 & 0.87 & -0.65 & 1.23 & -1.43 & 1.08 & $-3.49^{*}$ & -5.25 & -0.43 & $-7.56^{* *}$ & $-11.41^{*}$ & -1.04 & $-11.75^{* *}$ & $-15.10^{* *}$ \\
\hline DH16 x Altay & 0.44 & $8.60^{* *}$ & 2.94 & $-1.80^{* *}$ & 1.43 & -1.07 & 0.95 & -2.33 & $-6.09^{*}$ & 0.09 & 0.91 & -0.05 & 0.07 & -2.38 & -4.92 \\
\hline DH16 x Bezostaja & -0.46 & -0.27 & -0.60 & $1.89^{* *}$ & 1.63 & -0.52 & 0.18 & $-4.05^{*}$ & $-7.25^{*}$ & -0.02 & $-11.18^{* *}$ & $-13.31^{* *}$ & -0.34 & $-14.46^{* *}$ & $-18.79^{* * *}$ \\
\hline DH16 x Harmankaya & -0.73 & $6.31^{*}$ & 2.79 & $1.58^{*}$ & 2.78 & 1.47 & -1.05 & $-4.85^{* *}$ & $-10.39^{* *}$ & -0.29 & $-8.44^{* *}$ & -8.83 & 0.30 & $-9.20^{* *}$ & $-15.49^{* *}$ \\
\hline DH16 x Kate & 0.76 & $10.01^{* *}$ & 0.74 & $-1.67^{*}$ & -0.62 & -1.13 & -0.08 & $-4.64^{* *}$ & $-8.39^{* *}$ & 0.22 & -1.73 & -4.16 & -0.03 & $-9.48^{* *}$ & $-13.97^{* *}$ \\
\hline DH18 x Altay & 1.56 & $21.44^{* *}$ & $20.12^{* *}$ & 0.87 & 6.33 & 2.23 & 2.22 & 2.29 & -0.37 & -0.13 & 0.42 & -0.41 & 0.71 & 2.06 & 1.51 \\
\hline DH18 x Bezostaja & -1.47 & 5.26 & -1.56 & -0.14 & 0.51 & -0.19 & -1.92 & $-5.59^{* *}$ & $-9.91^{* *}$ & -0.22 & $-11.40^{* *}$ & $-13.42^{* *}$ & -0.37 & $-12.16^{* *}$ & $-18.25^{* *}$ \\
\hline DH18 x Harmankaya & 0.52 & $19.07^{* *}$ & $15.39^{*}$ & -0.27 & 1.85 & 1.67 & 0.11 & 0.07 & $-6.93^{*}$ & 0.06 & -4.21 & -4.48 & -0.47 & $-10.17^{* *}$ & $-18.00^{* *}$ \\
\hline DH18 x Kate & -0.61 & $15.73^{* *}$ & $12.78^{*}$ & -0.45 & 2.38 & 0.37 & -0.41 & -2.73 & $-7.74^{*}$ & 0.29 & 0.25 & -2.37 & 0.13 & $-6.52^{* *}$ & $-12.91^{* * *}$ \\
\hline DH19 x Altay & 0.87 & $8.50^{*}$ & 8.39 & 0.21 & 4.60 & 1.36 & 0.51 & 0.76 & $-6.60^{*}$ & -0.07 & 2.82 & 2.61 & 0.30 & 2.67 & -1.80 \\
\hline DH19 x Bezostaja & 0.22 & -0.19 & -5.60 & -1.04 & -1.49 & -2.95 & -1.21 & -2.72 & -3.13 & -0.27 & $-9.83^{* *}$ & $-10.97^{*}$ & -0.19 & $-9.53^{* *}$ & $-12.55^{* *}$ \\
\hline DH19 x Harmankaya & 1.12 & $10.14^{* *}$ & 8.00 & 0.50 & 1.94 & 1.30 & -0.78 & -0.04 & -2.30 & 0.36 & 0.23 & -0.51 & 0.45 & -4.09 & $-9.14^{*}$ \\
\hline DH19 x Kate & -2.21 & -0.37 & -4.04 & 0.33 & 2.48 & 1.28 & 1.47 & 2.71 & 2.49 & -0.01 & -0.31 & -3.88 & -0.57 & $-7.44^{* *}$ & $-10.42^{*}$ \\
\hline DH20 x Altay & -1.66 & -0.83 & $-10.50^{*}$ & -0.04 & 4.34 & 1.26 & -0.07 & $-5.50^{* *}$ & $-9.76^{* *}$ & 0.26 & $8.42^{* *}$ & 7.14 & 0.82 & 5.17 & 2.00 \\
\hline DH20 x Bezostaja & 2.80 & 4.55 & -0.43 & -0.04 & -0.19 & -1.81 & 1.59 & -2.66 & -5.26 & 0.42 & -1.60 & -4.17 & 0.08 & $-7.75^{* *}$ & $-12.05^{* *}$ \\
\hline DH20 x Harmankaya & -1.00 & 1.87 & -6.31 & -0.81 & 0.36 & -0.42 & -0.16 & $-4.51^{* *}$ & $-9.46^{* *}$ & -0.42 & -3.43 & -4.05 & -0.13 & $-6.06^{*}$ & $-12.22^{* *}$ \\
\hline DH20 x Kate & -0.13 & 3.43 & -9.64 & 0.89 & 3.26 & 2.20 & -1.35 & $-8.60^{* *}$ & $-11.60^{* *}$ & -0.25 & 0.54 & -1.75 & -0.76 & $-7.66^{* *}$ & $-11.88^{* *}$ \\
\hline DH21 x Altay & -0.14 & 3.10 & -1.24 & -0.49 & 3.47 & -0.39 & -1.65 & $-8.68^{* *}$ & $-15.02^{* *}$ & -0.14 & 3.84 & 2.15 & -0.78 & -3.23 & -4.40 \\
\hline DH21 x Bezostaja & 1.14 & 0.21 & -1.22 & 0.49 & 0.22 & -0.60 & $2.75^{*}$ & -0.44 & -0.45 & 0.30 & -3.60 & -3.77 & 0.94 & $-6.23^{* *}$ & $-12.17^{* *}$ \\
\hline DH21 x Harmankaya & -1.81 & -0.48 & -2.72 & -1.34 & -0.55 & -0.60 & -1.72 & $-7.97^{* *}$ & $-10.41^{* *}$ & -0.36 & -3.94 & -6.02 & -0.12 & $-8.16^{* *}$ & $-15.65^{* *}$ \\
\hline DH21 x Kate & 0.81 & 6.14 & -1.81 & 1.34 & 3.55 & 1.66 & 0.61 & $-4.90^{* *}$ & -5.50 & 0.20 & 3.14 & -1.94 & -0.04 & $-6.71^{* *}$ & $-12.54^{* *}$ \\
\hline DH22 x Altay & -0.94 & $8.89^{* *}$ & 5.24 & 0.68 & 9.30 & $9.30^{* *}$ & 1.19 & -2.94 & $-9.07^{* *}$ & 0.24 & 0.78 & -0.94 & -1.17 & -2.54 & -5.46 \\
\hline DH22 x Bezostaja & -0.53 & 3.33 & 0.94 & 0.03 & 3.56 & -1.09 & -2.03 & $-9.73^{* *}$ & $-10.36^{* *}$ & -0.37 & $-14.84^{* *}$ & $-15.05^{* *}$ & -0.59 & $-10.42^{* *}$ & $-14.62^{* *}$ \\
\hline DH22 x Harmankaya & 0.41 & $13.54^{* *}$ & $11.99^{*}$ & -0.93 & 3.92 & 0.09 & 2.16 & 0.56 & -2.79 & 0.15 & $-6.00^{*}$ & -8.10 & -0.56 & $-7.75^{* *}$ & $-13.80^{* *}$ \\
\hline DH $22 \times$ Kate & 1.07 & $15.28^{* *}$ & 7.56 & 0.22 & 6.26 & $4.16^{* *}$ & -1.33 & $-8.43^{* *}$ & $-9.65^{* *}$ & -0.02 & $-4.98^{*}$ & $-9.72^{*}$ & $2.31^{* *}$ & $5.61^{*}$ & 0.77 \\
\hline $\mathrm{SE}$ & 1.58 & & & 0.68 & & & 1.17 & & & 0.40 & & & 0.76 & & \\
\hline
\end{tabular}

${ }^{*} \mathrm{p} \leq 0.05,{ }^{*} \mathrm{p} \leq 0.01$. SCA: specific combining ability, HT: heterosis, HB: heterobeltiosis, SE: standard error 
All SCA values calculated for kernel color values were statistically insignificant and mostly negative. For the L value, significant SCA value were detected as negative only for the "DH6 x Altay" cross and only the "DH22 x Kate" had positive and significant SCA value for the b value cross (Table 4). Similarly, the heterosis and heterobeltiosis values of the grain color had negative values for almost all crosses. This result pointed to the presence of colors that turned darker and turned from white to red in the examined population. Red and white kernel color is controlled by three independent, homoeologous genes. Red color is dominant to white, and a single locus containing the dominant allele is sufficient to result in red color. The degree of red color is additive, with genotypes homozygous dominant at all three loci having the darkest red color, and only those homozygous recessive at all three genes being white. Therefore, the genetics of kernel color makes problematic to conversion of red to white kernel color (Sherman et al., 2008). The "DH19 x Kate" cross has to be followed as a cross for lighter grain color, "DH20 x Altay" for increasing the redness and "DH18 x Altay", "DH20 x Altay" and "DH22 x Kate" crosses for increasing the yellowness.

When the SCA effects of protein rate were examined, it was seen that the values changed between -0.81 and 0.93 and that the SCA effects were positive and significant in 13 crosses, insignificant in 3 crosses, and negative and significant values in others (Table 5). Thirteen of the cross combinations had positive and significant, while 11 had negative and significant heterosis. The highest heterosis value was detected in "DH21 x Altay" cross with $10.15 \%$. The heterobeltiosis values determined positively in 6 of the crosses were statistically significant in 4 crosses. It can be suggested DH20 and DH22 lines with a high observation average, positive GCA effect value for high protein bread wheat breeding. Within the crosses, "DH20 x Bezostaja", "DH22 x Kate", "DH22 x Harmankaya", "DH20 x Harmankaya", "DH21 x Altay", "DH21 Harmankaya", "DH6 x Altay" crosses showing high observation values, high positive SCA effect, high heterosis and heterobeltiosis can be considered as promising combinations. There were ten, nine, two, seven and one combinations relating to $\mathrm{Fe}, \mathrm{Zn}, \mathrm{Cu}, \mathrm{P}$ and $\mathrm{K}$ which had positive and significant SCA effects, respectively. In terms of Fe content, the majority of the crosses have exceeded the mean of parents and have positive and significant heterosis values, while nine crosses exceeding the superior parent have been identified (Table 5). Twelve of twenty-two crosses which had significant heterosis values was detected positive value for $\mathrm{Zn}$ content, and the heterobeltiosis values of seven of them were also positive. Most of the crosses for $\mathrm{Cu}, \mathrm{P}$, and $\mathrm{K}$ content exceed mean of parents, while the crosses that detected significant heterobeltiosis were mostly negative. "DH19 x Kate" for $\mathrm{Cu}$ content, "DH21 x Bezostaja", "DH21 x Harmankaya", "DH22 x Altay", "DH22 x Harmankaya" and "DH22 x Kate" crosses for P content are combinations that should be considered with both positive SCA values and high heterosis and heterobeltiosis values (Table 5). Crop improvement activities focus, first, on exploring the available genetic diversity for $\mathrm{Fe}, \mathrm{Zn}$. At the same time (or during subsequent screening), agronomic and end-use features are characterized (Pfeiffer and McClafferty, 2007). The combinations "DH6 x Kate", "DH20 x Bezostaja", "DH21 x Bezostaja" and "DH22 x Altay" came into prominence as promising combinations in terms of the $\mathrm{Fe}$ and $\mathrm{Zn}$ content and it can be possible to obtain biofortified lines by carrying these combinations to next generations. 
Table 5. Specific combining ability, heterosis and heterobeltiosis values of crosses for protein rate and concentrations of nutrient elements

\begin{tabular}{|c|c|c|c|c|c|c|c|c|c|c|c|c|c|c|c|c|c|c|}
\hline \multirow{2}{*}{ Crosses } & \multicolumn{3}{|c|}{ Protein rate $(\%)$} & \multicolumn{3}{|c|}{$\mathrm{Fe}\left(\mathrm{mg} \mathrm{kg}^{-1}\right)$} & \multicolumn{3}{|c|}{$\mathrm{Zn}\left(\mathrm{mg} \mathrm{kg}^{-1}\right)$} & \multicolumn{3}{|c|}{$\mathrm{Cu}\left(\mathrm{mg} \mathrm{kg}^{-1}\right)$} & \multicolumn{3}{|c|}{$P\left(\mathrm{mg} \mathrm{kg}^{-1}\right)$} & \multicolumn{3}{|c|}{$\mathrm{K}\left(\mathrm{mg} \mathrm{kg}^{-1}\right)$} \\
\hline & SCA & HT & HB & SCA & HT & HB & SCA & HT & HB & SCA & HT & HB & SCA & HT & HB & SCA & HT & HB \\
\hline H6 x Altay & $-0.80^{* *}$ & $-3.62^{* *}$ & $-5.79^{* *}$ & $6.13^{\text {** }}$ & -0.30 & $17.53^{* *}$ & $-6.80^{* * *}$ & $-18.85^{* *}$ & $-21.85^{* * *}$ & 0.14 & $-24.45^{* *}$ & $-26.58^{*}$ & 0.04 & $-6.79^{* *}$ & $-9.78^{* *}$ & 0.03 & $-7.09^{* *}$ & $-19.87^{* *}$ \\
\hline DH6 x Bezostaja & $0.58^{* * *}$ & $00^{* *}$ & $4.32^{* *}$ & $-8.62^{* *}$ & $-5.61^{* *}$ & $33.17^{* *}$ & $-5.37^{* *}$ & 3.43 & -4.96 & -0.27 & $-29.69^{* *}$ & $-37.19^{* *}$ & 0.10 & $6.42^{* *}$ & -6.49 & 0.14 & $-8.34^{* *}$ & $-20.72^{* *}$ \\
\hline DH6 x Harmankaya & $-0.38^{* *}$ & 0.10 & 1.22 & -1.07 & $-17.10^{* *}$ & $22.21^{* *}$ & $-5.20^{* *}$ & $-18.14^{* *}$ & $-28.36^{* *}$ & 0.60 & $-13.24^{*}$ & -15.57 & -0.03 & $-5.84^{* *}$ & $-9.89^{* *}$ & $-0.34^{* *}$ & $-19.01^{* *}$ & $-27.31^{* *}$ \\
\hline DH6 x Kate & $0.60^{* *}$ & $6.24^{* *}$ & $2.03^{* *}$ & $3.56^{* *}$ & $20.34^{* *}$ & $-9.43^{* *}$ & $17.36^{* *}$ & $17.79^{* *}$ & $89.42^{* *}$ & -0.48 & $-30.45^{* *}$ & $-37.10^{* *}$ & -0.11 & $-4.79^{* *}$ & $-7.14^{*}$ & 0.17 & $-10.33^{* *}$ & $-14.14^{* *}$ \\
\hline DH16 x Altay & $0.93^{* *}$ & $4.73^{* *}$ & -1.20 & $-7.60^{* *}$ & $-6.33^{* *}$ & $-19.42^{* *}$ & -0.45 & $26.73^{* *}$ & 6.28 & -0.45 & 2.08 & -0.76 & 0.12 & 0.08 & -3.50 & $-0.42^{* *}$ & $-8.99^{* *}$ & $-14.78^{* *}$ \\
\hline DH16 x Bezostaja & $-0.59^{* *}$ & $-5.13^{* *}$ & $-10.28^{* *}$ & $-1.36^{*}$ & $57.53^{* *}$ & $8.25^{* *}$ & 1.41 & $63.25^{* *}$ & $52.86^{* *}$ & 0.20 & 8.73 & 2.35 & 0.03 & $8.68^{* *}$ & -4.82 & 0.15 & 4.38 & -2.57 \\
\hline DH16 x Harı & $-0.64^{* *}$ & $-5.34^{* *}$ & $-11.51^{* *}$ & $4.49^{* *}$ & $16.01^{* *}$ & $10.79^{* *}$ & $2.14^{*}$ & $27.94^{* *}$ & -0.94 & 0.65 & $22.10^{* *}$ & 18.55 & $-0.52^{* * *}$ & $-17.41^{* *}$ & $-21.25^{* *}$ & 0.01 & 0.86 & -9.42 \\
\hline DH16 x Kate & $0.30^{* *}$ & 0.19 & $-3.84^{* *}$ & $4.47^{* *}$ & $71.43^{* *}$ & $5.70^{* * *}$ & $-3.10^{* *}$ & $15.97^{* *}$ & -10.66 & -0.41 & 3.28 & -1.50 & $0.37^{* *}$ & $15.12^{* *}$ & $11.86^{* *}$ & 0.25 & 2.46 & $-13.35^{* *}$ \\
\hline DH18 x Altay & $-0.37^{* *}$ & $-5.73^{* *}$ & $-7.07^{* *}$ & $-7.13^{* *}$ & $-46.52^{* *}$ & $51.85^{* *}$ & $1.93^{*}$ & 0.62 & $-14.12^{*}$ & 0.14 & $12.82^{*}$ & -0.95 & 0.07 & -3.28 & -4.09 & 0.16 & 0.13 & -7.57 \\
\hline DH18 x Bezostaja & $-0.19^{* * *}$ & $-3.97^{* *}$ & $-5.58^{* *}$ & $8.14^{* *}$ & $14.61^{* *}$ & $13.52^{* *}$ & $2.31^{* *}$ & $21.01^{* *}$ & $15.62^{*}$ & -0.35 & 4.39 & -0.47 & $0.17^{*}$ & $12.53^{* *}$ & 2.58 & 0.02 & $-7.85^{* *}$ & $-14.67^{* *}$ \\
\hline DH18 x Harm: & $0.36^{* *}$ & 0.29 & -0.19 & $-6.60^{* *}$ & $-44.79^{* *}$ & $-46.67^{* *}$ & $-3.97^{* *}$ & $-45.21^{* *}$ & $-56.92^{* *}$ & 0.21 & $17.19^{* *}$ & 2.78 & -0.12 & $-6.23^{* *}$ & -6.53 & -0.06 & $-8.96^{* *}$ & $-12.25^{* *}$ \\
\hline DH18 x Kate & $0.20^{* *}$ & $-1.79^{* *}$ & $-4.90^{\text {*** }}$ & $5.59^{* *}$ & $7.92^{* *}$ & $-12.67^{* *}$ & -0.28 & -4.09 & $-24.97^{* *}$ & -0.00 & $10.93^{*}$ & 4.39 & -0.12 & -2.25 & -3.82 & -0.12 & $-14.21^{* * *}$ & $-16.95^{* *}$ \\
\hline DH19 x Altay & $0.31^{* *}$ & $-1.24^{* *}$ & $-7.45^{* *}$ & $-6.44^{* *}$ & $-28.56^{* *}$ & $-43.53^{* *}$ & $-4.97^{* *}$ & $16.54^{* * *}$ & -6.90 & $-1.46^{* *}$ & $-19.05^{* *}$ & $-27.50^{* *}$ & $-0.49^{* * *}$ & $-22.72^{* *}$ & $-27.18^{* *}$ & -0.13 & 1.31 & -4.04 \\
\hline DH19 x Bezostaja & $0.63^{* *}$ & $1.29^{* *}$ & $-4.85^{* *}$ & -0.88 & $33.34^{* *}$ & $27.61^{* *}$ & $-1.97^{*}$ & $63.01^{* *}$ & $44.28^{* *}$ & 0.51 & 4.97 & 2.30 & -0.08 & 0.76 & $-13.56^{* *}$ & 0.02 & 1.31 & -3.73 \\
\hline DH19 x Harmankaya & -0.13 & $-3.67^{* *}$ & $-10.54^{* *}$ & $13.38^{* * *}$ & $18.60^{* *}$ & $-14.98^{* *}$ & $9.75^{* *}$ & $94.87^{* *}$ & $44.61^{* *}$ & -1.14 & $-11.20^{*}$ & $-20.57^{*}$ & $0.18^{*}$ & 1.83 & -5.10 & 0.02 & 2.06 & 1.06 \\
\hline DH19 x Kate & $-0.81^{* *}$ & $-8.87^{* *}$ & -13.12 & & & -1.75 & $-2.80^{* *}$ & $36.52^{* *}$ & 0.84 & & & $22.00^{*}$ & $0.40^{* *}$ & $12.17^{* *}$ & 6.49 & 0.09 & -1.01 & -6.66 \\
\hline DH20 x Altay & -0.12 & $2.33^{* *}$ & $-5.56^{* *}$ & $8.07^{\text {** }}$ & $6.43^{* *}$ & $-13.04^{* *}$ & $2.84^{* *}$ & 2.06 & -1.69 & $1.34^{*}$ & $16.81^{* *}$ & 1.92 & 0.02 & -1.88 & -6.42 & 0.06 & $11.26^{* *}$ & -4.93 \\
\hline $\mathrm{DH} 20 \times \mathrm{Be}$ & $0.62^{* *}$ & & -0.48 & -0.57 & $22.28^{* *}$ & $22.15^{* *}$ & $1.81^{*}$ & $10.52^{* *}$ & 1.55 & -0.15 & -3.54 & -8.66 & $0.26^{* *}$ & $17.87^{* *}$ & 2.22 & $-0.34^{* *}$ & -2.69 & $-16.62^{* * *}$ \\
\hline DH20 x Ha & 0.11 & $4.44^{* *}$ & $-4.46^{* *}$ & $-3.43^{* *}$ & $-29.58^{* *}$ & $-48.12^{* *}$ & 1.49 & $-15.12^{* *}$ & $-25.71^{* *}$ & -0.11 & 1.80 & -11.27 & $-0.23^{* *}$ & $-6.74^{* *}$ & $-12.04^{* *}$ & $0.34^{* *}$ & $14.38^{* *}$ & 1.64 \\
\hline DH20 x Kate & $-0.61^{* *}$ & $-1.16^{* *}$ & $-7.23^{* *}$ & $-4.06^{* *}$ & $8.76^{* *}$ & -0.96 & $-6.13^{* *}$ & $-37.87^{* *}$ & $-45.95^{* *}$ & -1.08 & $-12.50^{*}$ & -18.21 & -0.05 & 2.84 & -1.17 & -0.06 & 0.51 & -4.77 \\
\hline DH21 x Altay & $0.78^{* *}$ & $10.15^{* *}$ & $8.37^{* *}$ & $-5.62^{* *}$ & $-23.29^{* *}$ & $-33.12^{* *}$ & $-2.85^{* *}$ & $-17.47^{* *}$ & $-17.62^{* *}$ & 0.40 & $12.74^{*}$ & -4.47 & -0.15 & 0.90 & -1.24 & 0.18 & $19.52^{* *}$ & 2.76 \\
\hline $\mathrm{DH} 21 \times \mathrm{Be}$ & $-0.42^{* *}$ & $2.04^{* *}$ & 0.66 & $9.84^{* *}$ & $67.00^{* *}$ & $54.84^{* *}$ & $5.28^{* *}$ & $47.36^{* *}$ & $31.07^{* *}$ & 0.25 & 8.58 & -0.46 & 0.03 & $20.59^{* *}$ & $11.26^{* *}$ & -0.04 & $10.06^{* *}$ & -5.11 \\
\hline $\mathrm{DH} 21 \times \mathrm{H}$ & $0.14^{*}$ & $6.29^{* *}$ & $3.59^{* *}$ & $-4.30^{* * *}$ & $-23.13^{* *}$ & $-40.22^{* *}$ & -1.25 & $-16.90^{* * *}$ & $-24.92^{* *}$ & -0.14 & 9.45 & -7.35 & $0.46^{* *}$ & $25.72^{* *}$ & $24.49^{* * *}$ & -0.04 & $10.47^{* *}$ & -1.20 \\
\hline DH21 x Kate & $-0.50^{* *}$ & $0.73^{*}$ & 0.54 & 0.08 & $30.62^{* *}$ & $28.23^{* * *}$ & -1.18 & 0.24 & -10.00 & -0.50 & 2.25 & -7.43 & $-0.34^{* *}$ & 1.68 & -1.24 & -0.10 & $4.37^{*}$ & -0.42 \\
\hline DH 22 x Altay & $-0.73^{* *}$ & $-6.41^{* *}$ & $-15.54^{* *}$ & $12.58^{* *}$ & $48.39^{* * *}$ & $8.60^{* *}$ & $10.31^{* *}$ & $61.21^{\text {** }}$ & $46.77^{* *}$ & -0.11 & $19.13^{* *}$ & 5.85 & $0.39^{* *}$ & $26.11^{* *}$ & $20.96^{* *}$ & 0.12 & $20.21^{* *}$ & 4.53 \\
\hline DH22 x Bezostaja & $-0.62^{* *}$ & $-5.30^{* * *}$ & $-14.35^{* *}$ & $-6.55^{* *}$ & $35.01^{* *}$ & $16.76^{* *}$ & $-3.47^{* *}$ & 1.88 & $-16.61^{* *}$ & -0.19 & $15.07^{* *}$ & 11.17 & $-0.50^{* *}$ & $8.94^{* *}$ & -5.04 & 0.05 & $14.44^{* *}$ & -0.20 \\
\hline DH22 x Harmankay & $0.55^{* *}$ & $2.40^{* * *}$ & $-8.39^{* *}$ & $-2.47^{* *}$ & $-8.31^{* *}$ & $-38.29^{* *}$ & $-2.96^{* *}$ & $-15.20^{* * *}$ & $-15.77^{* *}$ & -0.07 & $23.34^{* *}$ & 9.46 & $0.26^{* *}$ & $25.48^{* *}$ & $19.02^{* * *}$ & 0.06 & $14.84^{* *}$ & 3.95 \\
\hline $\mathrm{H} 22 \times$ Kate & $0.81^{* * *}$ & $3.15^{* *}$ & $-5.37^{* *}$ & $-3.56^{* *}$ & $43.27^{* *}$ & $14.66^{* *}$ & $-3.88^{* *}$ & -4.23 & -5.54 & 0.38 & $24.56^{* *}$ & 18.75 & -0.14 & $16.00^{* *}$ & $12.12^{* *}$ & -0.23 & 3.19 & -0.27 \\
\hline SE & 0.07 & & & 0.55 & & & 0.82 & & & 0.58 & & & 0.08 & & & 0.13 & & \\
\hline
\end{tabular}

${ }^{*} \mathrm{p} \leq 0.05,{ }^{*} \mathrm{p} \leq 0.01$. SCA: specific combining ability, HT: heterosis, HB: heterobeltiosis, SE: standard error 


\section{Selection of genotypes and breeding strategy for grain quality and biofortified capacity}

Principal component analysis (PCA) is a method which defined plant properties which contributed most to the present variation within a group of genotypes. In addition, it helps breeders for genetic advancement of characters that have low heritability specifically in early generations via indirect selection, just as the selection of parental lines for breeding purpose (Golparvar et al., 2006; Ahmadizadeh and Felenji, 2011). Cumulative variability of four factors was $26.01 \%, 41.49 \%, 56.22 \%$ and $69.32 \%$, respectively (Table 6). Different characters have different pattern of contribution for principal components. For PC1, all characters were positively contributing except L, b, $\mathrm{Zn}, \mathrm{P}$ and $\mathrm{Cu}$, whereas for $\mathrm{PC} 2$ only six component were positively contributing, also for PC3 and PC4, seven component were negatively contributing (Table 7).

Kernel length, kernel width, kernel thickness, kernel volume, thousand kernel weight and hectolitre weight constituted the first component so called physical kernel characters which had the highest factors loadings. Kernel hardness, L, a, b values which can be called as the color properties were the second component, and the third and fourth components included the kernel sphericity, protein rate and nutrient elements.

Table 6. Eigen value and contribution of the principal component axes towards variation in line $x$ tester bread wheat hybrids

\begin{tabular}{c|ccc|ccc}
\hline \multirow{2}{*}{ Component } & \multicolumn{3}{|c|}{ Initial } & \multicolumn{3}{c}{ Variamax rotation } \\
\cline { 2 - 7 } & Eigenvalues & Variance (\%) & Cumulative (\%) & Eigenvalues & Variance (\%) & Cumulative (\%) \\
\hline 1 & 4.512 & 26.543 & 26.543 & 4.422 & 26.012 & 26.012 \\
3 & 3.208 & 18.871 & 45.414 & 2.632 & 15.482 & 41.494 \\
4 & 2.370 & 13.942 & 59.355 & 2.503 & 14.723 & 56.217 \\
5 & 1.694 & 9.963 & 69.319 & 2.227 & 13.102 & 69.319 \\
6 & 1.343 & 7.899 & 77.218 & & & \\
7 & 1.025 & 6.029 & 83.246 & & & \\
8 & 0.713 & 4.195 & 87.441 & & & \\
9 & 0.590 & 3.469 & 90.910 & & & \\
10 & 0.484 & 2.846 & 93.756 & & & \\
11 & 0.357 & 2.099 & 95.854 & & & \\
12 & 0.264 & 1.556 & 97.410 & & \\
13 & 0.191 & 1.124 & 98.535 & & \\
14 & 0.127 & 0.748 & 99.282 & & \\
15 & 0.069 & 0.407 & 99.689 & & \\
16 & 0.051 & 0.300 & 99.989 & & \\
17 & 0.002 & 0.010 & 99.999 & & \\
\hline & 0.000 & 0.001 & 100.000 & & \\
& & & & & \\
& & & & & \\
\end{tabular}


Table 7. Eigen value and contribution of the principal component axes towards variation in line $x$ tester bread wheat hybrids

\begin{tabular}{l|c|c|c|c}
\hline & PC1 & PC2 & PC3 & PC4 \\
\hline Kernel length & $\mathbf{0 . 6 8 1}$ & -0.150 & -0.552 & 0.302 \\
Kernel width & $\mathbf{0 . 8 9 3}$ & 0.060 & 0.222 & 0.152 \\
Kernel thickness & $\mathbf{0 . 9 2 5}$ & -0.001 & 0.056 & -0.058 \\
Kernel volume & $\mathbf{0 . 9 6 9}$ & -0.006 & -0.056 & 0.151 \\
Kernel sphericity & 0.471 & 0.198 & $\mathbf{- 0 . 7 4 5}$ & -0.239 \\
Kernel hardness & 0.120 & $\mathbf{- 0 . 5 7 3}$ & -0.308 & -0.121 \\
Thousand kernel weight & $\mathbf{0 . 7 5 0}$ & 0.014 & 0.136 & -0.015 \\
Hectolitre weight & $\mathbf{0 . 6 5 0}$ & -0.150 & -0.516 & -0.111 \\
L & -0.187 & $\mathbf{0 . 7 5 2}$ & 0.063 & -0.292 \\
a & 0.066 & $\mathbf{0 . 7 2 3}$ & 0.175 & 0.134 \\
b & -0.029 & $\mathbf{0 . 8 7 9}$ & 0.173 & 0.048 \\
Protein rate & 0.042 & -0.094 & $\mathbf{- 0 . 8 1 3}$ & 0.437 \\
Fe & 0.016 & -0.334 & $\mathbf{0 . 6 3 5}$ & -0.232 \\
$\mathrm{Zn}$ & -0.208 & -0.403 & $\mathbf{0 . 1 2 7}$ & 0.126 \\
$\mathrm{Cu}$ & -0.021 & 0.153 & -0.044 & $\mathbf{0 . 7 6 9}$ \\
$\mathrm{P}$ & -0.051 & -0.220 & 0.228 & $\mathbf{0 . 6 5 5}$ \\
$\mathrm{K}$ & 0.237 & 0.010 & 0.094 & $\mathbf{0 . 7 8 5}$ \\
\hline
\end{tabular}

Bi-plot analysis was performed based on two principal components for relationships between variables and genotypes (Fig. 3). Genotypes and variables were presented in single bi-plot graph to further simplify the visualization. Physical kernel characters, protein rate, color values and $\mathrm{Fe}$ content contributed maximum towards the total variability present in the evaluated germplasm. Therefore, these traits might be considered selecting effectively of parents for hybridization program to improvement of genetic potential in bread wheat kernel quality in the population as well as to develop elite lines or new $F_{1}$ crosses. Moreover, selection of the genotypes had high kernel quality and biofortified capacity should be suggested as one of the best breeding strategy for genetic advancement of bread wheat. According to bi-plot graph, there was high variability in the examined genotypes. "DH20 x Altay", "DH19 x Altay", DH20, DH22, "DH21 x Altay", "DH20 x Bezostaja", "DH18 x Altay", "DH22 x Harmankaya" and "DH20 x Harmankaya" can be identified as the best genotypes as these genotypes grouped in positive part as well as they can be easily identified as distinct or farthest from the rest of the genotype groups of the bi-plot (Fig. 3). Genotypes "DH6 $\mathrm{x}$ Harmankaya", "DH20 x Harmankaya" and "DH22 x Harmankaya" were reflected much better performance compared to the rest of genotypes for physical kernel characters. The "DH6 x Kate" genotype, had high Fe and Zn content, can be specifically selected to breed biofortified variety. 


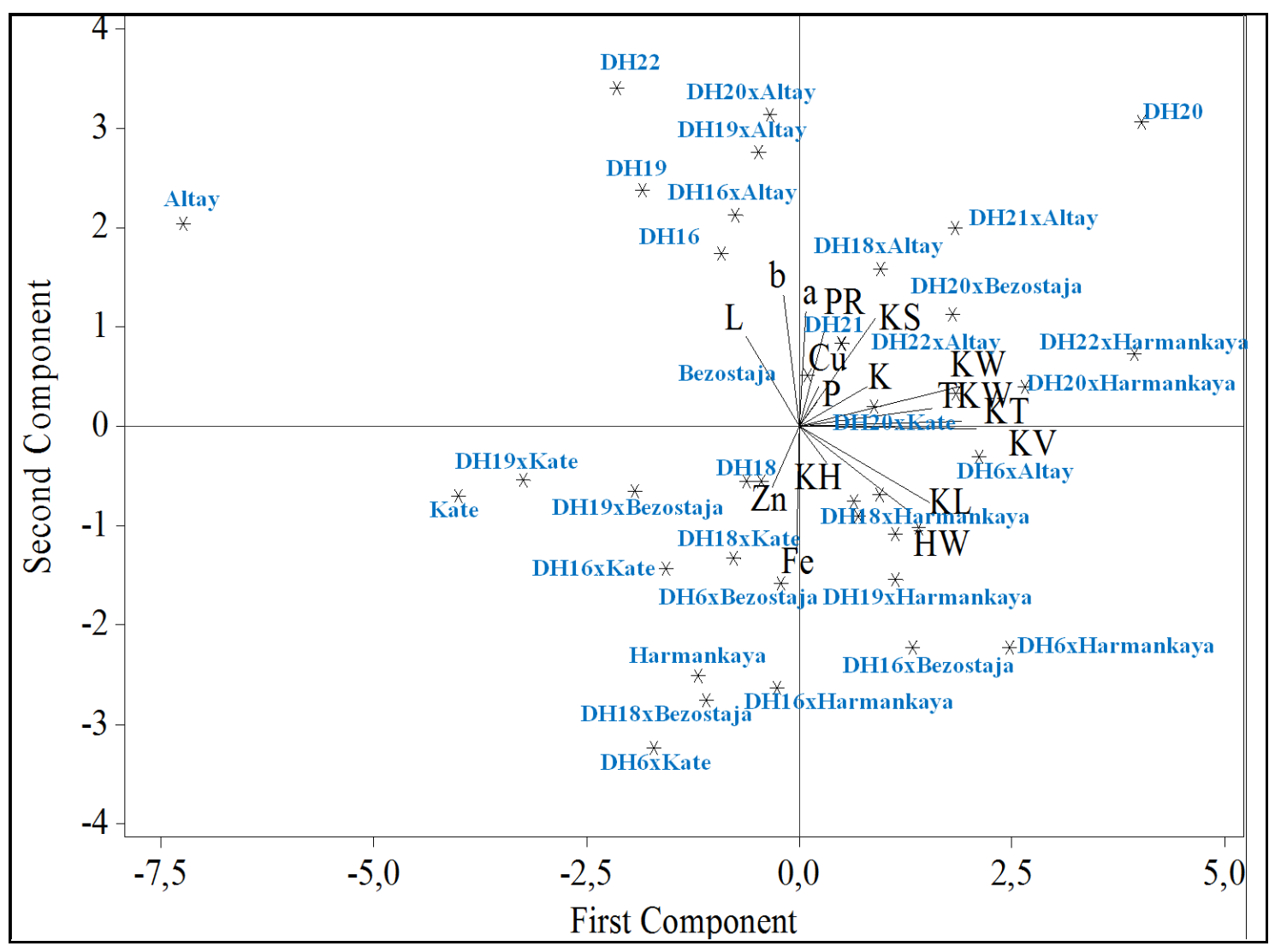

Figure 3. Principal component bi-plot of 39 bread wheat genotypes between 17 kernel quality characters. (Contribution of first component $=26.01 \%$, second component $=15.48 \%$ )

\section{Conclusions}

The population examined in this study has sufficient variation to be assessed in breeding programs in terms of both end-use quality characteristics and biofortification. The predominance of non-additive type of gene actions clearly showed that selection of superior crops should be delayed to $\mathrm{F}_{4}$ or $\mathrm{F}_{5}$ generations. The lines DH6, DH22 and the tester Harmankaya were good combiners for the flour yield and milling quality. The lines DH21, DH22 and the tester Kate were good combiners for protein rate and biofortified crops. The DH22 line, in particular, is well-suited to be a favourite of breeding programs for this purpose with both end-use quality and biofortified capacity. "DH6 x Harmankaya", "DH20 x Harmankaya", "DH22 x Harmankaya", "DH6 x Kate", "DH20 x Altay", "DH19 x Altay", "DH21 x Altay", "DH20 x Bezostaja" and "DH18 x Altay" was found as the best crosses to all examined traits. Because "DH20 $\mathrm{x}$ Harmankaya", "DH22 x Harmankaya", "DH21 x Altay" and "DH18 x Altay" had both the best SCA and they grouped in positive part of the bi-plot, these crosses are particularly important as promising crosses for biofortification and end-use quality.

It is clear that genetic biofortification offer sustainable solutions to the escalating micronutrient-related malnutrition problems. However, biofortified crops must also be suitable for producers and consumer demands. Therefore, biofortification and end-use quality traits are highly complementary. This research provides general information about the inheritance of wheat quality, and plant breeding strategies for the bioavailability of micronutrients in modern cultivars. This information will light on the 
molecular researches about genes controlled these properties, functional genomic analyzes and the creation of association maps in the future. In addition, examined wheat population has a potential occurring both high quality and nourishing candidate varieties for the countries with high malnutrition prevalence in the near future.

\section{REFERENCES}

[1] AACCI (2000): Approved Methods of the American Association of Cereal Chemists Methods, 08-01, 32-23, 32-32, 44-19, 46-30, 55-10, 55-31 (10th ed.). - The Association, St. Paul, MN, U. S. A.

[2] Abbaspour, N., Hurrell, R., Kelishadi, R. (2014): Review on iron and its importance for human health. - Journal of Research in Medical Sciences: The Official Journal Of Isfahan University Of Medical Sciences 19(2): 164.

[3] Ahmadizadeh, M., Felenji, H. (2011): Evaluation diversity among potato cultivars using agro-morphological and yield components in fall cultivation of Jiroft area. - AmericanEurasian Journal of Agriculture and Environmental Science 11(5): 655-662.

[4] Aslam, R., Munawar, M., Salam, A. (2014): Genetic architecture of yield components accessed through line $\times$ tester analysis in wheat (Triticum aestivum L.). - Universal Journal of Plant Science 2(5): 93-96.

[5] Bálint, A. F., Kovács, G., Erdei, L., Sutka, J. (2001). Comparison of the Cu, Zn, Fe, Ca and $\mathrm{Mg}$ contents of the grains of wild, ancient and cultivated wheat species. - Cereal Research Communications 29(3-4): 375-382.

[6] Barton, C. J. (1948): Photometric analysis of phosphate rock. - Anal. Chem. 20(11): 1068-1073.

[7] Cakmak, I. (2008): Enrichment of cereal grains with zinc: agronomic or genetic biofortification? - Plant and Soil 302(1-2): 1-17.

[8] Cakmak, I., Torun, A., Millet, E., Feldman, M., Fahima, T., Korol, A. Nevo, E., Braun, H. J., Özkan, H. (2004): Triticum dicoccoides: an important genetic resource for increasing zinc and iron concentration in modern cultivated wheat. - Soil Sci. Plant Nutr. 50: $1047 \mathrm{e} 1054$.

[9] Chasapis, C. T., Loutsidou, A. C., Spiliopoulou, C. A., Stefanidou, M. E. (2012): Zinc and human health: an update. - Archives of Toxicology 86(4): 521-534.

[10] Chiang, M. S., Smith, J. D. (1967): Diallel analysis of inheritance of quantitative characters in grain sorghum. I. heterosis and inbreeding depression. - Can. Journal Genetic Cytology 9: 44-51.

[11] De Peuw, R. M., McCetc, T. N. (1988): Utilization of sodium hydroxide to assess kernel color and its inheritance in eleven spring wheat varieties. - Can. J. Plant Sci. 68: 323-329.

[12] Dziki, D., Laskowski, J. (2005): Wheat kernel physical properties and milling process. Acta Agrophysica 6(1): 59-71.

[13] Falconer, D. S. (1980): Introduction to Quantitative Genetics. - Oliver and Boyd Ltd., London.

[14] Ferreira, M. S. L., Martre, P., Mangavel, C., Girousse, C., Rosa, N. N., Samson, M., More, M. (2012): Physicochemical control of durum wheat grain filling and glutenin polymer assembly under different temperature regimes. - J. Cereal Sci. 56: 58-66.

[15] Fonseca, S. M., Patterson, F. L. (1968): Hybrid vigor in a seven parent diallel cross in common winter wheat (Triticum aestivum L.). - Crop. Science 8: 85-88.

[16] Golparvar, A. R., Ghasemi-Pirbalouti, A., Madani, H. (2006): Genetic control of some physiological attributes in wheat under drought stress conditions. - Pakistan Journal of Biological Sciences 9(8): 1442-1446.

[17] Gomez-Becerra, H. F., Erdem, H., Yazici, A., Tutus, Y., Torun, B., Ozturk, L., Cakmak, I. (2010): Grain concentrations of protein and mineral nutrients in a large collection of 
spelt wheat grown under different environments. - Journal of Cereal Science 52(3): 342349.

[18] Graham, R., Senadhira, D., Beebe, S., Iglesias, C., Monasterio, I. (1999): Breeding for micronutrient density in edible portions of staple food crops: conventional approaches. Field Crops Research 60(1-2): 57-80.

[19] He, F. J., MacGregor, G. A. (2008): Beneficial effects of potassium on human health. Physiologia Plantarum 133(4): 725-735.

[20] Henderson, L., Irving, K., Gregory, J. (2003): The National Diet \& Nutrition Survey: Adults Aged 19-64 Years. Vol. 3. - Her Majesty's Stationery Office, London.

[21] Hruskova, M., Svec, I. (2009): Wheat hardness in relation to other quality factors. Czech J. Food Science 27: 240-248.

[22] Istipliler, D., Ilker, E., Tonk, F. A., Civi, G., Tosun, M. (2015): Line x tester analysis and estimating combining abilities for yield and some yield components in bread wheat. Turk. J. Field Crops 20(1): 72-77.

[23] Khan, A. A., Iqbal, M., Ali, Z., Athar, M. (2010): Diallelic analysis of quantitative traits in hexaploid wheat (Triticum aestivum L.). - Plant Biosystems 144(2): 373-380.

[24] Kirk, S., Sawyer, R. (1991): Pearson's Composition and Analysis of Foods (Ed. 9). Longman Group Ltd., Harlow, UK.

[25] Korkut, K. Z., Baser, I., Bilgin, O. (2001): Genotypic and phenotypic variability, heritability and phenotypic correlation for yield and yield components in bread wheat varieties. - Acta Agronomica Hungarica 49(3): 237-242.

[26] Kumar, B., Bharadwaj, D. N., Singh, L., Gupta, S. K. (2017): Estimation of combining ability in $F_{1}$ and $F_{2}$ generations of diallel crosses in winter wheat (Triticum aestivum $\mathrm{L}$. Em. Thell). - Int. J. Curr. Microbiol. App. Sci. 6(12): 1432-1444.

[27] Longin, C. F., Gowda, M., Mühleisen, J., Ebmeyer, E., Kazman, E., Schachschneider, R., Schacht, J., Kirchhoff, M., Zhao, Y., Reif, J. C. (2013): Hybrid wheat: quantitative genetic parameters and consequences for the design of breeding programs. - Theor. Appl. Genet. 126(11): 2791-2801.

[28] Maphosa, L., Langridge, P., Taylor, H., Parent, B., Emebiri, L. C., Kuchel, H., Reynolds, M. P., Chalmers, K. J., Okada, A., Edwards, J., Mather, D. E. (2014): Genetic control of grain yield and grain physical characteristics in a bread wheat population grown under a range of environmental conditions. - Theor Appl Genet. 127: 1607-1624.

[29] McNeal, F. H., Balridge, D. E., Berg, M. A., Watson, C. A. (1965): Evaluation of three hard red spring wheat crosses for heterosis. - Crop Science 5: 399-400.

[30] Mohsenin, N. N. (1986): Physical Properties of Plant and Animal Materials. 2nd ed. Gordon and Breach, New York.

[31] Nuttall, J. G., O’Leary, G. J., Panozzo, J. F., Walker, C. K., Barlow, K. M., Fitzgerald, G. J. (2017): Models of grain quality in wheat - A review. - Field Crops Research 202: 136145 .

[32] Ozcan, K. (1999): Developing of a statistical package program for population genetics. $\mathrm{PhD}$. Thesis, University of Aegean, Institute of Science, Izmir.

[33] Perenzin, M., Pogna, N. E., Borghi, B. (1992): Combining ability for bread making quality in wheat. - Can. J. Plant Science 72: 743-754.

[34] Pfeiffer, W. H., McClafferty, B. (2007): HarvestPlus: Breeding Crops for Better Nutrition. - Crop Sci. 47(S3): S88-S105.

[35] Pomeranz, Y. (1964): Wheat Chemistry and Technology (edited). - American Association of Cereal Chemists, St. Paul, Minnesota.

[36] Ponce-García, N., Ramírez-Wong, B., Escalante-Aburto, A., Torres-Chávez, P. I., de Dios Figueroa-Cárdenas, J. (2016): Mechanical Properties in Wheat (Triticum aestivum) Kernels Evaluated by Compression Tests: A Review. - Viscoelastic and Viscoplastic Materials, InTech, Rijeka. 
[37] Schuler, S. F., Bacon, R. K., Finney, P. L., Gbur, E. E. (1995): Relationship of test weight and kernel properties to milling and baking quality in soft red winter wheat. - Crop Science 35(4): 949-953.

[38] Sherman, J. D., Souza, E., See, D., Talbert, L. E. (2008): Microsatellite markers for kernel color genes in wheat. - Crop Science 48(4): 1419-1424.

[39] Stern, B. R., Solioz, M., Krewski, D., Aggett, P., Aw, T., Baker, S., Crump, K., Dourson, M., Haber, L., Hertzberg, R., Keen, C., Meek, B., Rudenko, L., Schoeny, R., Slob, W., Starr, T. (2007): Copper and human health: biochemistry, genetics, and strategies for modeling dose-response relationships. - Journal of Toxicology and Environmental Health, Part B. 10(3): 157-222.

[40] Velu, G., Singh, R. P., Huerta-Espino, J., Peña, R. J., Arun, B., Mahendru-Singh, A., YaqubMujahid, M., Sohu, V. S., Mavi, G. S., Crossa, J., Alvarado, G., Joshi, A. K., Pfeiffer, W. H. (2012): Performance of biofortified spring wheat genotypes in target environments for grain zinc and iron concentrations. - Field Crops Research 137: 261267.

[41] Weisstein, E. W. (2018): Ellipsoid. - MathWorld-A, Wolfram Web Resource. http://mathworld.wolfram.com/Ellipsoid.html. Access date: 25.07.2018.

[42] Zhao, F. J., McGrath, S. P. (2009): Biofortification and phytoremediation. - Curr. Opin. Plant Biol. 12: 373e380. 